\title{
OPEN Structural and physical properties of 99 complex bulk chalcogenides crystals using first-principles calculations
}

\author{
Sahib Hasan ${ }^{1}$, Khagendra Baral ${ }^{1}$, Neng $\mathrm{Li}^{2 \bowtie}$ \& Wai-Yim Ching ${ }^{1 \bowtie}$ \\ Chalcogenide semiconductors and glasses have many applications in the civil and military fields, \\ especially in relation to their electronic, optical and mechanical properties for energy conversion and \\ in enviormental materials. However, they are much less systemically studied and their fundamental \\ physical properties for a large class chalcogenide semiconductors are rather scattered and incomplete. \\ Here, we present a detailed study using well defined first-principles calculations on the electronic \\ structure, interatomic bonding, optical, and mechanical properties for 99 bulk chalcogenides including \\ thirteen of these crytals which have never been calculated. Due to their unique composition and \\ structures, these 99 bulk chalcogenides are divided into two main groups. The first group contains \\ 54 quaternary crystals with the structure composition $\left(A_{2} B C Q_{4}\right)(A=A g, C u ; B=Z n, C d, H g, M g, S r$, \\ $\mathrm{Ba} ; \mathrm{C}=\mathrm{Si}, \mathrm{Ge}, \mathrm{Sn} ; \mathrm{O}=\mathrm{S}, \mathrm{Se}, \mathrm{Te})$, while the second group contains scattered ternary and quaternary \\ chalcogenide crystals with a more diverse composition $\left(\mathrm{A}_{\mathrm{x}} \mathrm{B}_{\mathrm{y}} \mathrm{C}_{\mathrm{z}} \mathrm{Q}_{\mathrm{n}}\right)(\mathrm{A}=\mathrm{Ag}, \mathrm{Cu}, \mathrm{Ba}, \mathrm{Cs}, \mathrm{Li}, \mathrm{Tl}, \mathrm{K}, \mathrm{Lu}, \mathrm{Sr}$; \\ $B=\mathrm{Zn}, \mathrm{Cd}, \mathrm{Hg}, \mathrm{Al}, \mathrm{Ga}, \mathrm{In}, \mathrm{P}, \mathrm{As}$, La, Lu, Pb, Cu, Ag; C = Si, Ge, Sn, As, Sb, Bi, Zr, Hf, Ga, In; Q = S, Se, \\ Te; $x=1,2,3 ; y=0,1,2,5 ; z=0,1,2$ and $n=3,4,5,6,9)$. Moreover, the total bond order density \\ (TBOD) is used as a single quantum mechanical metric to characterize the internal cohesion of these \\ crystals enabling us to correlate them with the calculated properties, especially their mechanical \\ properties. This work provides a very large database for bulk chalcogenides crucial for the future \\ theoretical and experimental studies, opening opportunities for study the properties and potential \\ application of a wide variety of chalcogenides.
}

In materials research, a large amount of efforts were related to energy conversion, mostly focusing in converting solar energy to other forms of energy such as electric, thermal, and chemical ${ }^{1-6}$. Of particular interest are materials that can convert energy in the mid and far infrared (IR) range of radiation. Such materials can be used in a variety of civilian and military applications such as infrared sensors, optical communications, imaging technology and remote sensing ${ }^{7-10}$, atmospheric monitoring, radar and laser guidance ${ }^{11}$, laser frequency modulators ${ }^{12}$, and medical visualization ${ }^{13}$. The materials with narrow energy gaps and containing heavy elements that can be more effective in thermoelectric conversion are actively investigated ${ }^{14-16}$. In this regard, the ternary and quaternary chalcogenides play an important role because of their excellent performance for the above applications. There are many binary and ternary chalcogenide crystals can be easily doped by n-type elements or p-type elements to increase the conductivity in the thermoelectric applications ${ }^{17}$. Chalcogenides contain at least one of the chalcogen elements ( $\mathrm{S}, \mathrm{Se}, \mathrm{Te}$ ) and one or more electropositive (or electronegative in a few cases) elements. The electropositive elements are generally from group IB (Cu, Ag), IIB ( $\mathrm{Zn}, \mathrm{Cd}, \mathrm{Hg}$ ), IVA (Si, Ge, Sn), IIIA (In, Tl), IVB (Zr, Hf), IIA (Mg, Ba), and IA (Li, K, Cs) in the Periodic Table. In some cases, lanthanide elements such as $\mathrm{La}, \mathrm{Lu}$ and othercan also be involved. This extremely diverse compositional space makes chalcogenide compounds a unique class of materials rarely seen in other materials classes such as semiconductors, large gap insulators, superconductors, silicates glasses, metallic alloys, etc. It is the formation of various possible chemical bonds between these elements that makes chalcogenides a special class of materials with diverse structures and properties. As a matter of fact, the energy band gaps for the 99 chalcogenide crystals reported in this paper range from $0.004 \mathrm{eV}-2.50 \mathrm{eV}$ which makes them suitable for many aforementioned applications. Within the

\footnotetext{
${ }^{1}$ Department of Physics and Astronomy, University of Missouri-Kansas City, Kansas City, Missouri 64110, USA. ${ }^{2}$ School of Materials Science and Engineering, Wuhan University of Technology, No. 122, Luoshi Road,

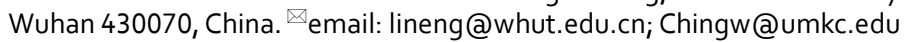


last decade, many of quaternary chalcogenide crystals, such as the $\mathrm{A}^{\mathrm{I}}-\mathrm{B}^{\mathrm{III}}-\mathrm{C}^{\mathrm{IV}}-\mathrm{X}^{\mathrm{VI}}$ system (where $\mathrm{A}^{\mathrm{I}}=\mathrm{Cu}, \mathrm{Ag}$; $\mathrm{B}^{\mathrm{III}}=\mathrm{Ga}$, In; $\mathrm{C}^{\mathrm{IV}}=\mathrm{Ge}, \mathrm{Si} ; \mathrm{X}^{\mathrm{VI}}=\mathrm{S}, \mathrm{Se}$ ), or $\mathrm{A}^{\mathrm{I}}{ }_{2} \mathrm{~B}^{\mathrm{II}} \mathrm{C}^{\mathrm{IV}} \mathrm{Q}_{4}$ system (where $\mathrm{A}^{\mathrm{I}}=\mathrm{Cu}, \mathrm{Ag} ; \mathrm{B}^{\mathrm{II}}=\mathrm{Mg}, \mathrm{Mn}, \mathrm{Fe}, \mathrm{Zn}, \mathrm{Cd}$, and $\mathrm{Hg} ; \mathrm{C}^{\mathrm{IV}}=\mathrm{Si}, \mathrm{Ge}, \mathrm{Sn}$; and $\left.\mathrm{Q}=\mathrm{S}, \mathrm{Se}, \mathrm{Te}\right)$, have attracted a great deal of attention due to their compositional flexibility and functional turning ability that makes them ideal for thermoelectric devices ${ }^{18-22}$, optical devices ${ }^{23}$, nonlinear optical devices in the visible-infrared region and photovoltaic cells ${ }^{3,24-30}$, solar energy converters ${ }^{31-34}$, and magnetic applications ${ }^{35}$. Another group of chalcogenide crystals in the form of $\mathrm{Ag}_{2} \mathrm{XYSe}_{4}(\mathrm{X}=\mathrm{Ba}, \mathrm{Sr} ; \mathrm{Y}=\mathrm{Ge}$, $\mathrm{Sn}$ ) also become attractive because of their ability in converting heat energy to electricity ${ }^{36}$. Most recent studies show that quaternary chalcogenide crystals with compositions $\mathrm{A}^{\mathrm{I}} \mathrm{B}^{\mathrm{II}} \mathrm{C}^{\mathrm{IV}} \mathrm{Q}_{4}$ and $\mathrm{A}_{2}^{\mathrm{I}} \mathrm{B}^{\mathrm{II}} \mathrm{C}^{\mathrm{IV}} \mathrm{Q}_{5}$ such as in $\mathrm{BaZnSiSe}_{4}$, $\mathrm{SrCdGeSe}_{4}$, and $\mathrm{Ba}_{2} \mathrm{AsGaSe}_{5}$ are crucial in medical and military applications due to their ideal infrared nonlinear optical (NLO) properties and high visible-light-induced photocatalytic reactivity ${ }^{37-39}$. Only a small fraction of such NLO materials with second harmonic generation (SHG) effect are commercially available. Materials such as $\mathrm{Ag}_{2} \mathrm{BaGeS}_{4}, \mathrm{Ag}_{2} \mathrm{BaGeSe}_{4}, \mathrm{Ag}_{2} \mathrm{BaSnS}_{4}$, and $\mathrm{Ag}_{2} \mathrm{BaSnSe}_{4}$ could be SHG active for different applications and they are now at the center of the chalcogenide research ${ }^{40} . \mathrm{Cu}_{2} \mathrm{SrSiS}_{4}$ and $\mathrm{Cu}_{2} \mathrm{SrSnS}_{4}$ show high LDT (laser damage threshold) and excellent SHG performance and that makes them promising materials for IR NLO applications ${ }^{41,42}$ . Unfortunately, there is a lack of comprehensive study on their electronic structure and physical properties. In the present work, we provide a comprehensive library of structural, electronic, optical and elastic properties for 99 chalcogenide crystals using first-principles calculations. They are divided into two groups: $\left(\mathrm{A}_{2} \mathrm{BCQ}_{4}\right)($ with $\mathrm{A}=\mathrm{Ag}, \mathrm{Cu} ; \mathrm{B}=\mathrm{Zn}, \mathrm{Cd}, \mathrm{Hg}, \mathrm{Mg}, \mathrm{Sr}, \mathrm{Ba} ; \mathrm{C}=\mathrm{Si}, \mathrm{Ge}, \mathrm{Sn} ; \mathrm{Q}=\mathrm{S}, \mathrm{Se}, \mathrm{Te})$ and $\left(\mathrm{A}_{\mathrm{x}} \mathrm{B}_{\mathrm{y}} \mathrm{C}_{\mathrm{z}} \mathrm{Q}_{\mathrm{n}}\right)(\mathrm{A}=\mathrm{Ag}, \mathrm{Cu}, \mathrm{Ba}, \mathrm{Cs}, \mathrm{Li}$, Tl, K, Lu, Sr; B = Zn, Cd, Hg, Al, Ga, In, P, As, La, Lu, Pb, Cu, Ag; C = Si, Ge, Sn, As, Sb, Bi, Zr, Hf, Ga, In; Q = $\mathrm{S}, \mathrm{Se}, \mathrm{Te})$ and $(\mathrm{x}=1,2,3 ; \mathrm{y}=0,1,2,5 ; \mathrm{z}=0,1,2, \mathrm{n}=3,4,5,6,9)$. The fully optimized structures are listed in Table S1 with the corresponding experimental lattice parameters. Such a comprehensive study enables us to make important correlations among different properties in getting a broader view. In particular, we advocate the use of a single quantum mechanical metric that describes the strength and the internal cohesion of the crystal, the total bond order density (TBOD). In the following section, we briefly describe the computational methods which were used to do the calculations, followed by the results and discussions section. Focus will be on the optical, bonding, and mechanical properties, and their correlations with the TBOD. We end up with a brief conclusion and our vision for the future study of chalcogenide crystals and glasses.

\section{Methods}

In this work, two well-defined density functional theory (DFT) based methods were used: the Vienna Ab initio Simulation Package (VASP) $)^{43,44}$ and the orthogonal linear combination of atomic orbitals (OLCAO) method ${ }^{45}$. VASP was used to optimize the crystal structures and to calculate the mechanical properties. The PerdewBurke-Ernzerhof (PBE) generalized-gradient-approximation (GGA) ${ }^{46}$ was used for the exchange and correlation potential in solving the Kohn-Sham equation with an energy cut-off of $500 \mathrm{eV}$. This energy cut-off has been carefully tested for all crystals and it is found to be the best choice balancing the fast convergence and accurate ground state energy. For the VASP calculation, the Monkhorst scheme ${ }^{47}$ with different k-point mesh ranging from $9 \times 9 \times 5$ and $5 \times 9 \times 5$ was used for $\mathrm{Ba}_{4} \mathrm{AgInS}_{6}$ (48 atoms) and $\mathrm{Ag}_{2} \mathrm{In}_{2} \mathrm{SiSe}_{6}$ (44 atoms) respectively to $8 \times 9 \times 9$ for medium sized crystals such as $\mathrm{Cu}_{2} \mathrm{ZnSiSe}_{4}(16$ atoms). The electronic and ionic force convergence criteria were set at $10^{-6} \mathrm{eV}$ and $10^{-4} \mathrm{eV} / \AA ̊$ respectively. The VASP optimized structures for all crystals were used as input to calculate the electronic structure, interatomic bonding, and optical properties using the OLCAO method with different choice of basis size for each atom in the database $\mathrm{e}^{45}$. The use of localized atomic orbitals in the basis expansion in contrast to the plane-wave expansion is particularly effective for calculating the electronic structure and interatomic bonding for both crystalline $e^{48-52}$ and non-crystalline materials ${ }^{53,54}$ especially those with complex structures typical in the biomolecular systems ${ }^{55,56}$. In the OLCAO calculation, a sufficient number of $\mathrm{k}$-points mesh were used for band structure and density of states (DOS) calculations based on the size of crystal. For interatomic bonding, a more localized minimal basis $(\mathrm{MB})$ set is used based on Mulliken scheme ${ }^{57}$. Equations (1) and (2) show the formulae for effective charge $\left(Q_{\alpha}^{*}\right)$ and bond order (BO) values, or the overlap population $\rho_{\alpha \beta}$ between any pair of atoms $(\alpha, \beta)$.

$$
\begin{gathered}
Q_{\alpha}^{*}=\sum_{i} \sum_{m, o c c} \sum_{j, \beta} C_{i \alpha}^{* m} C_{j \beta}^{m} S_{i \alpha, j \beta} \\
\rho_{\alpha \beta}=\sum_{m, o c c} \sum_{j, \beta} C_{i \alpha}^{* m} C_{j \beta}^{m} S_{i \alpha, j \beta}
\end{gathered}
$$

In the above equation, $S_{i \alpha, j \beta}$ are the overlap integrals between the ith orbital in $\alpha$ th atom and the $j$ th orbital in $\beta$ th atom. $C_{j \beta}^{m}$ is the eigenvector coefficients of the $m$ th occupied band. The BO from Eq. (2) defines the relative strength of the bond. The summation of all BO values in the crystal gives the total bond order (TBO). When normalized by the cell volume, we obtain the total bond order density (TBOD). TBOD is a single quantum mechanical metric to describe the internal cohesion of the crystal $^{58}$. It can be conveniently decomposed into partial components or the partial bond order density (PBOD) for any structural units or groups of bonded atoms. The details for the calculation of interatomic bonding, optical, and mechanical properties are described in the Sects. 1 and 2 in the Supplementary Information (SI). The orthogonalized linear combination of atomic orbitals (OLCAO) method was used to calculate the electronic structures and partial charge distributions of the chalcogenide crystals under study. The OLCAO method is an all-electron method based on the local density approximation of DFT. It uses the atomic orbitals expanded in Gaussian-type orbitals (GTO) in the basis expansion. This method is particularly efficient for calculating the electronic structure of different systems. In the present calculation, a full basis set, which consisted of the core orbitals, occupied valence orbitals, and the next 
empty shell of unoccupied orbitals for each atom, was used for the self-consistent potential and the density of states (DOS) calculations. The more localized minimal basis was used for partial charges calculation under the Mulliken scheme. The partial charge $\Delta Q$ on each atom is defined as the deviation of charge from the calculated effective charge $Q^{*}$ from the neutral atom charge $\left(Q_{0}\right)$ or $\Delta Q=Q_{0}-Q^{*}$. So negative $\delta Q$ implies gain of electrons or electronegative and positive $\Delta Q$ means loss of electron or electropositive.

\section{Results and discussion}

Table $\mathrm{S} 1$ in the SI lists the 99 quaternary crystals of the first group $\left(\mathrm{A}_{2} \mathrm{BCQ}_{4}\right)(1-54)$ and the second group $\left(A_{x} B_{y} C_{z} Q_{n}\right)$ (55-99). The data presented includes the name of the crystal, its space group, the VASP relaxed crystal parameters, and the available experimental parameters with appropriate references. In all subsequent discussions, the same specific order and the ID number labeled for the crystal are maintained to avoid any confusion. To make it easier for the readers to identify the specific crystal, we add the ID number in front of the crystal name most of the time. In both groups, we distinguish the chalcogen elements by referring them as $Q$, and the other elements by A, B, and C. Any exceptions will be specifically mentioned.

Electronic structure. The most important quantity in a crystal to understand its physical and chemical properties is its electronic structure. The calculated results for the band structures and the density of states (DOS) for the 99 chalcogenide crystals are shown in Figs. S1 and S2 respectively. Table S2 shows the comparison between our calculated direct (D) and indirect (ID) band gaps (Eg), and the experimentally data or other theoretical calculations with references cited for these 99 crystals. Among them, 67-BaZnSiSe ${ }_{4}$ has the largest Eg of $2.494 \mathrm{eV}$, whereas $18-\mathrm{Cu}_{2} \mathrm{HgGeSe}_{4}$ has the smallest Eg of $0.005 \mathrm{eV}$. The crystals $21-\mathrm{Cu}_{2} \mathrm{HgSnSe}{ }_{4}, 62-\mathrm{Cu}_{2} \mathrm{GeSe}_{3}$, 95- $\mathrm{Tl}_{2} \mathrm{CdGeSe}_{4}, 96-\mathrm{Tl}_{2} \mathrm{CdSnSe}_{4}, 97-\mathrm{Tl}_{2} \mathrm{HgGeSe}_{4}, 98-\mathrm{Tl}_{2} \mathrm{HgSiSe}_{4}$, and 99- $\mathrm{Tl}_{2} \mathrm{HgSnS}$ are metals or semi-metals with zero band gaps. We have identified the following 13 crystals for specific focused discussion: $10-\mathrm{Cu}_{2} \mathrm{CdSiSe}_{4}$, 16- $\mathrm{Cu}_{2} \mathrm{CdSnTe} \mathrm{H}_{4}, 37-\mathrm{Cu}_{2} \mathrm{MgSnTe}_{4}, 64-\mathrm{Ag}_{2} \mathrm{SnTe}_{3}, 66-\mathrm{Ag}_{4} \mathrm{P}_{2} \mathrm{Se}_{6}, 69-\mathrm{BaHg}_{2} \mathrm{As}_{2} \mathrm{~S}_{6}, 74-\mathrm{Ba}_{2} \mathrm{LaGaSe}_{5}, 75-\mathrm{Ba}_{2} \mathrm{LuGaSe}_{5}$, 76- $\mathrm{Ba}_{2} \mathrm{LuInSe}_{5}, 95-\mathrm{Tl}_{2} \mathrm{CdGeSe}_{4}, 96-\mathrm{Tl}_{2} \mathrm{CdSnSe}{ }_{4}, 97-\mathrm{Tl}_{2} \mathrm{HgGeSe}_{4}$, and $99-\mathrm{Tl}_{2} \mathrm{HgSnS}$. They are marked bold in Table S2. These crystals are the first-time theoretical studied for their electronic structure, optical, and mechanical properties and some of them have unique properties mentioned above. They are shown in Figs. 1, 2, 3, and 4 , respectively. As can be seen, some are semiconductors or insulators $\left(10-\mathrm{Cu}_{2} \mathrm{CdSiSe} \mathrm{S}_{4}, 16-\mathrm{Cu}_{2} \mathrm{CdSnTe}_{4}\right.$, 37- $\mathrm{Cu}_{2} \mathrm{MgSnTe}_{4}, 64-\mathrm{Ag}_{2} \mathrm{SnTe}_{3}, 66-\mathrm{Ag}_{4} \mathrm{P}_{2} \mathrm{Se}_{6}, 69-\mathrm{BaHg}_{2} \mathrm{As}_{2} \mathrm{~S}_{6}, 74-\mathrm{Ba}_{2} \mathrm{LaGaSe}_{5}, 75-\mathrm{Ba}_{2} \mathrm{LuGaSe}$, and $76-\mathrm{Ba}_{2} \mathrm{~L}-$ $\left.\mathrm{uInSe}_{5}\right)$ and the others are actually metals with no band gaps $\left(95-\mathrm{Tl}_{2} \mathrm{CdGeSe}{ }_{4}, 96-\mathrm{Tl}_{2} \mathrm{CdSnSe} e_{4}, 97-\mathrm{Tl}_{2} \mathrm{HgGeSe}_{4}\right.$, and $99-\mathrm{Tl}_{2} \mathrm{HgSnS}_{4}$ ).

Partial charge. An important electronic structure property in a crystal is the distribution of the partial charge (PC) on each atom in the crystal. PC is the deviation of the effective charge $Q^{*}$ from the neutral atom charge $Q_{0}$ or simply the charge transfer. The calculated $Q^{*}$ on each atom in the 99 chalcogenide crystals is listed in column 3 of Table S3. The generally accepted concept is that chalcogen elements $(\mathrm{S}, \mathrm{Se}, \mathrm{Te})$ receive electrons from the other atoms in the chalcogenide compounds or they are electronegative. The other atoms in a chalcogenide compound (except for $\mathrm{Cu}$ and $\mathrm{Ag}$ in most cases) lose charge and they are mostly electropositive. It turns out that this generally accepted notion is grossly over-simplified, and the real situation is far more complicated and subtle. With 99 chalcogenide crystals formed by 30 elements, we are in the unique position to analyze the PC distribution and charge transfer mechanism in much greater detail than for just one or a few crystals. In the first group with the structure $\left(\mathrm{A}_{2} \mathrm{BCQ}_{4}\right)$, the $\mathrm{PC}$ values for most of $\mathrm{A}$ elements are negative similar to the chalcogen elements except for some crystals such as $36-\mathrm{Ag}_{2} \mathrm{ZnSiS}_{4}, 38-\mathrm{Ag}_{2} \mathrm{ZnSnSe}$, and $39-\mathrm{Ag}_{2} \mathrm{CdGeS}_{4}$ where the A element (Ag) loses charge. While the B and $\mathrm{C}$ elements have positive PC. To explain why $\mathrm{Cu}$ and $\mathrm{Ag}$ are electronegative in most of the crystals in group one, we must dig deeper. $\mathrm{Cu}$ and $\mathrm{Ag}$ are noble metals with full shell of $103 \mathrm{~d}$ and $104 \mathrm{~d}$ electrons respectively, and metals usually lose charge to the other elements in the chemical compound, specially to the nonmetals elements, but our calculations for the partial charge and effective charge indicate that these two elements $(\mathrm{Cu}, \mathrm{Ag})$ can gain or loss charge depending on chalcogen elements their interact. First, for crystals that contain $\mathrm{Cu}$ and $\mathrm{Ag}$ with the nonmetal chalcogen elements $(\mathrm{S}, \mathrm{Se})$ and later with $\mathrm{Te}$ (a metalloid element) which is very different than $\mathrm{S}$ and Se. The bonding properties indicate that $\mathrm{Cu}$ and $\mathrm{Ag}$ have two types of bonds. depending on the chalcogen elements ( $\mathrm{S}$ or Se). They form bonds that are ionic bonds (metal-nonmetal bond), and between two metal elements ( $\mathrm{Cu}, \mathrm{Ag}) . \mathrm{Cu}$ and $\mathrm{Ag}$ lose charge to the nonmetallic chalcogen elements $S$ and Se and these bonds occur at shorter bond lengths (1.5-2.0 $)$. The other type of bonds is between $\mathrm{Cu}$ or $\mathrm{Ag}$ and with one of the metal elements $\mathrm{Zn}$ and $\mathrm{Cd}$ and with one of the alkaline earth elements ( $\mathrm{Mg}, \mathrm{Sr}, \mathrm{Ba})$. These bonds occur at long bond lengths (>3.8 $\AA$ ). In this type of complex bonding, $\mathrm{Cu}$ and $\mathrm{Ag}$ can attract or pull the charge from $\mathrm{Zn}, \mathrm{Cd}, \mathrm{Mg}, \mathrm{Sr}$, and $\mathrm{Ba}$ elements since $\mathrm{Cu}$ and $\mathrm{Ag}$ have much higher electronegativity. Our calculations show that under these scenario, $\mathrm{Cu}$ and $\mathrm{Ag}$ are electronegative. On the other hand, the $\mathrm{Cu}-\mathrm{Te}$ and $\mathrm{Ag}-\mathrm{Te}$ bonds are much more complicated because $\mathrm{Te}$ is metalloid element. It sometimes acts like metal element and lose charge and sometimes behaves like a nonmental element and gain charge. In the second group $\left(A_{x} B_{y} C_{z} Q_{n}\right)$, almost all $A, B$, and $C$ elements ( $A g, C u, Z n, C d, S i, S n, G e, I n, P, A l, S b, G a, B i$, $\mathrm{La}, \mathrm{Lu}, \mathrm{Cs}, \mathrm{K}, \mathrm{Li}, \mathrm{Sr}$ ) lose charges to the chalcogen elements, except for Ba, which gains charges. To the best of our knowledge, this new conspicuous property on complex chalcogenides has not been reported anywhere in either computational or experimental studies. The above results on PC distribution are summarized in Figs. S3, S4 and S5. Because of the large number on the non-chalcogen elements in the 99 crystals, the calculation of their PC for each element from each crystal is a monumental task but could be extremely revealing. For the benefit of easier presentation, we split the plot for the non-chalcogen elements in two figures Fig. S3 with 13 elements $(\mathrm{Cu}, \mathrm{Ag}, \mathrm{Zn}, \mathrm{Cd}, \mathrm{Hg}, \mathrm{Al}, \mathrm{Ga}, \mathrm{In}, \mathrm{Tl}, \mathrm{Si}, \mathrm{Ge}, \mathrm{Sn}, \mathrm{Pb})$ and Fig. S4 with 14 elements (P, As, Sb, Bi, Li, K, Cs, Mg, Sr, $\mathrm{Ba}, \mathrm{Zr}, \mathrm{Hf}, \mathrm{La}, \mathrm{Lu})$ while keep the display for the three chalcogen elements (S, Se, Te) in Fig. S5. The horizontal 
(10) $\mathrm{Cu}_{2} \mathrm{CdSiSe}_{4}$

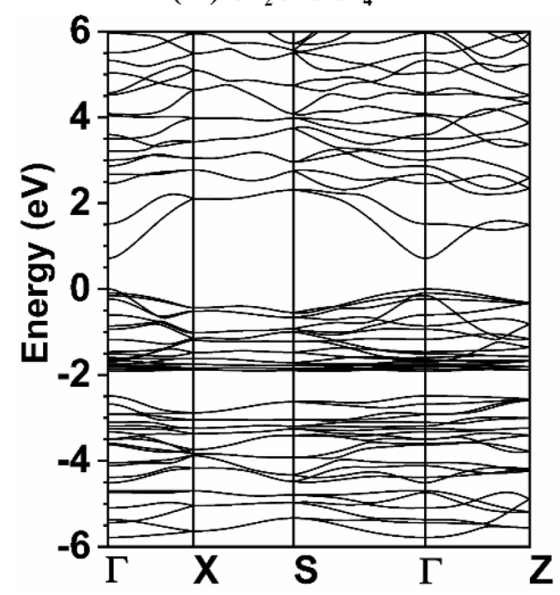

(64) $\mathrm{Ag}_{2} \mathrm{SnTe}_{3}$

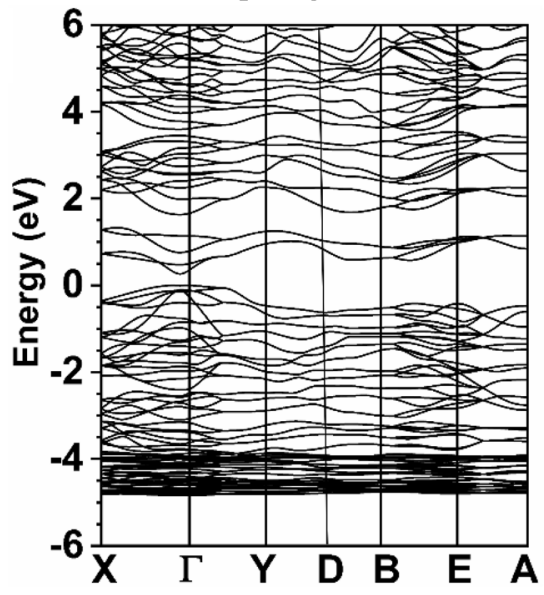

(16) $\mathrm{Cu}_{2} \mathrm{CdSnTe}_{4}$

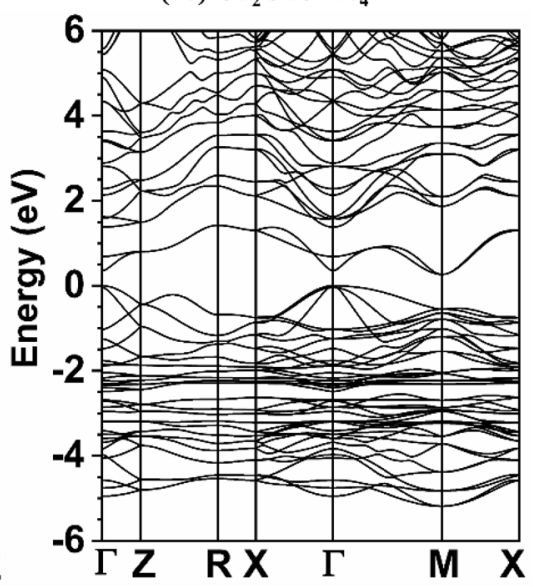

(66) $\mathrm{Ag}_{4} \mathrm{P}_{2} \mathrm{Se}_{6}$

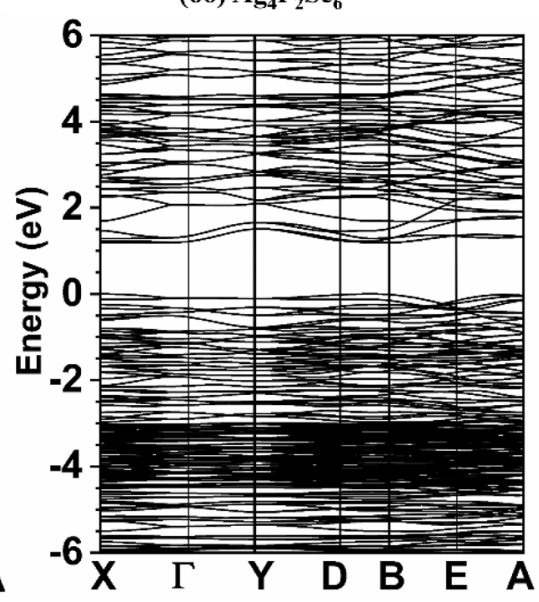

(37) $\mathrm{Cu}_{2} \mathrm{MgSnTe}_{4}$

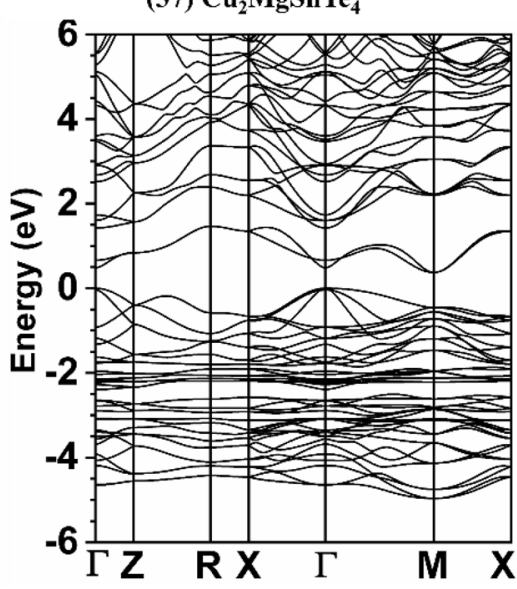

(69) $\mathrm{BaHg}_{2} \mathrm{As}_{2} \mathrm{~S}_{6}$

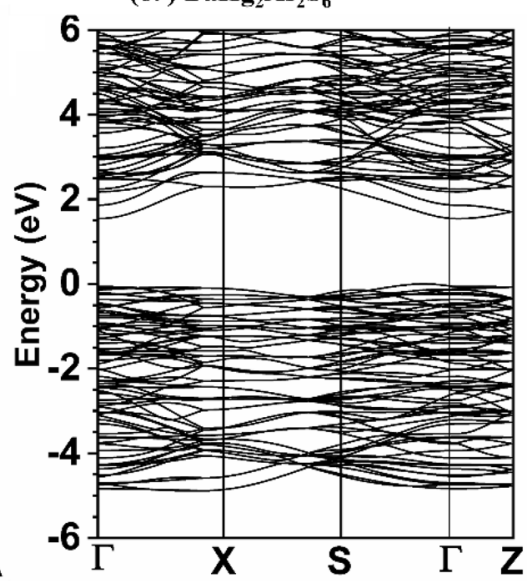

Figure 1. Calculated band structure of: $\mathrm{Cu}_{2} \mathrm{CdSiSe}{ }_{4}, \mathrm{Cu}_{2} \mathrm{CdSnTe}{ }_{4}, \mathrm{Cu}_{2} \mathrm{MgSnTe}_{4}, \mathrm{Ag}_{2} \mathrm{SnTe}_{3}, \mathrm{Ag}_{4} \mathrm{P}_{2} \mathrm{Se}_{6}$, $\mathrm{BaHg}_{2} \mathrm{As}_{2} \mathrm{~S}_{6}$.

bar in each column indicate the averaged PC for that element. Figure S3 shows the PC distribution of the first 13 elements. Depending on the crystals they originate, they generally have a wide range of scatted values and only $\mathrm{Cu}$ has an average negative $\mathrm{PC}$ of $-0.104 \mathrm{e}^{-}$and $\mathrm{Ag}$ has a slightly positive average charge of $0.026 \mathrm{e}^{-}$. From $\mathrm{Zn}$ to $\mathrm{Pb}$, the average $\mathrm{PC}$ range from $0.310 \mathrm{e}^{-}$in $\mathrm{Zn}$ to $0.811 \mathrm{e}^{-}$in Cd with most of them having close average values. An important facet is a wide scattering of PC values for individual crystals indicating the averaged PC value for any element in chalcogenide crystals has no real meaning since it depends on the crystal components and the overall charge transfers between them. The situation is slightly different in Fig. S4 for the 14 elements from P to Lu mainly because there are much less crystals involving these group of elements. One of the spectacular outliers of the rare earth element $\mathrm{La}$ from a single crystal 74- $\mathrm{Ba}_{2} \mathrm{LaGaSe}_{5}$. Other outliers include Ba which consists of 11 crystal distinctively separated into 2 groups with average PC of $1.729 \mathrm{e}^{-}$between them. The most important PC information is the distribution of the three chalcogen elements in Fig. S5.

The range from $-1.255 \mathrm{e}^{-}$to $-0.216 \mathrm{e}^{-}$in $\mathrm{S},-1.018 \mathrm{e}^{-}$to $-0.125 \mathrm{e}^{-}$in Se, and $-0.247 \mathrm{e}^{-}$to $+0.083 \mathrm{e}^{-}$in Te with average $\mathrm{PC}$ are $-0.475 \mathrm{e}^{-},-0.437 \mathrm{e}^{-}$and $-0.064 \mathrm{e}^{-}$respectively. In the sulfides, $77-\mathrm{Ba}_{4} \mathrm{AgInS}_{6}(\mathrm{PC}=-1.255$ $\left.\mathrm{e}^{-}\right)$and $71-\mathrm{Ba}_{2} \mathrm{AlSbS}_{5}\left(\mathrm{PC}=-1.033 \mathrm{e}^{-}\right)$are far more negative than the other crystals. The selenides have a slightly less negative PC than the sulfides with three of them more negative than the rest. They are $\left(74-\mathrm{Ba}_{2} \mathrm{LaGaSe}_{5}\right.$, 72- $\mathrm{Ba}_{2} \mathrm{GaBiSe}_{5}$ and 73- $\mathrm{Ba}_{2} \mathrm{AsGaSe}_{5}$ with PC of $-1.018 \mathrm{e}^{-},-0.919 \mathrm{e}^{-}$and $-0.867 \mathrm{e}^{-}$respectively. On the other hand, for the tellurides, four crystals $\left(19-\mathrm{Cu}_{2} \mathrm{MgGeTe}_{4}, 3-\mathrm{Cu}_{2} \mathrm{ZnSiTe}_{4}, 22-\mathrm{Cu}_{2} \mathrm{HgSnTe}_{4}, 8-\mathrm{Cu}_{2} \mathrm{ZnSnTe}_{4}\right)$ actually have positive PCs of $0.083 \mathrm{e}^{-} .0 .062 \mathrm{e}^{-}, 0.020 \mathrm{e}^{-}$and $0.007 \mathrm{e}^{-}$respectively. The spectacular nature of the diverse distribution of PC in all the elements in the 99 complex bulk chalcogenide compounds is remarkable and each data point for the PC of each atom can be traced to the specific crystal among the 99 crystals.

Interatomic bonding. An important characteristics is to investigate the interatomic bonding between every pair of atoms in the crystal represented by the $\mathrm{BO}$ value that quantifies the strength of the bond ${ }^{58}$. These data can then be used to obtain the key parameter TBOD discussed in the method section. The highest TBOD among these 99 crystals is in $1-\mathrm{Cu}_{2} \mathrm{ZnSiS}_{4}$ followed by $32-\mathrm{Cu}_{2} \mathrm{MgSiS}_{4}$, while the lowest TBOD is from $77-\mathrm{Ba}_{4} \mathrm{~A}$ gInS $_{6}$ closely followed by $72-\mathrm{Ba}_{2} \mathrm{GaBiSe}_{5}$ (see Table S3). In Figs. 5 and 6, we display the TBOD for the 99 crystals in 2 main groups respectively. The first group with 54 crystals $\left(A_{2} B C Q_{4}\right)$, is divided into two subgroups $(\mathrm{Cu}-$ 
(74) $\mathrm{Ba}_{2} \mathrm{LaGaSe}_{5}$

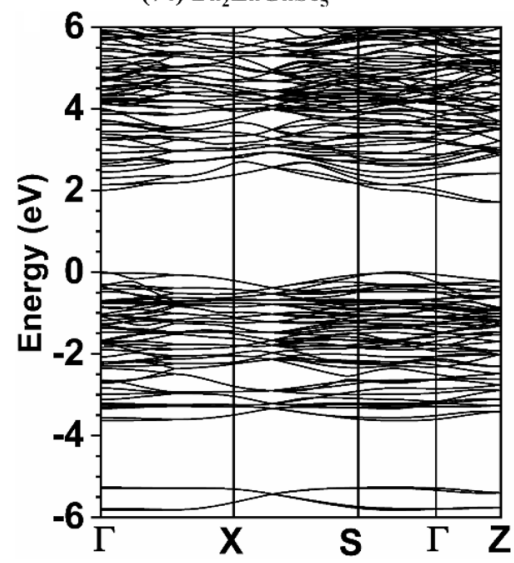

(95) $\mathrm{Tl}_{2} \mathrm{CdGeSe}_{4}$

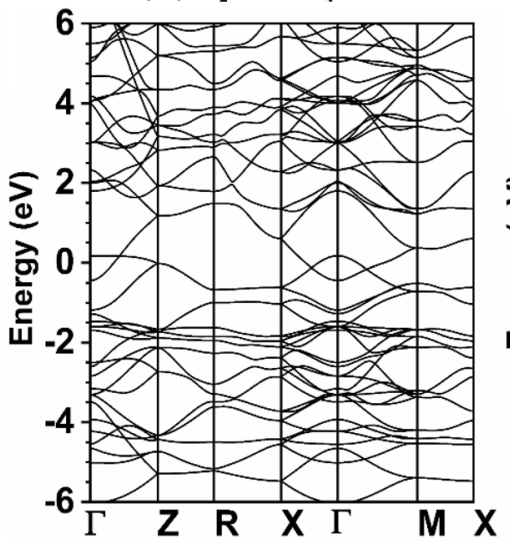

(99) $\mathrm{Tl}_{2} \mathrm{HgSnS}_{4}$

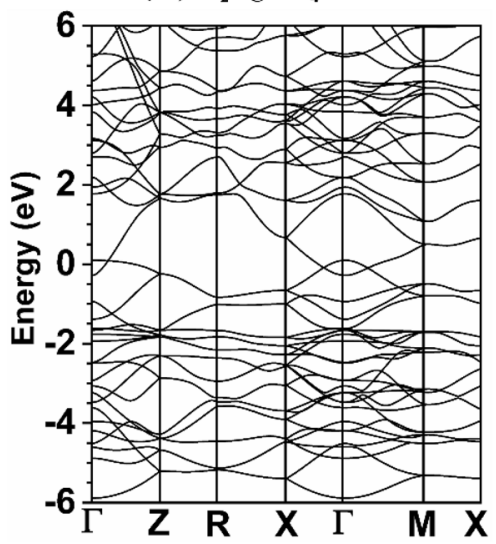

(75) $\mathrm{Ba}_{2} \mathrm{LuGaSe}_{5}$

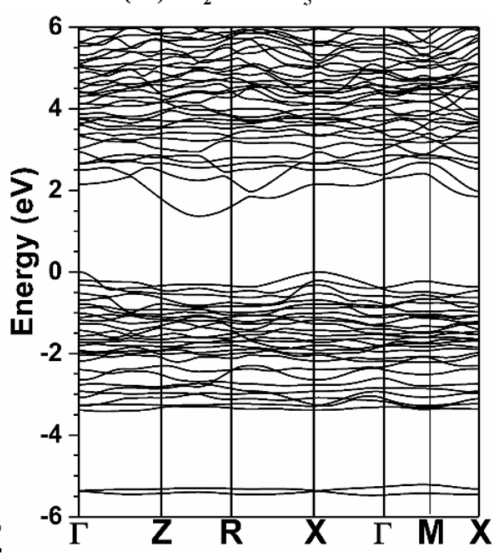

(96) $\mathrm{Tl}_{2} \mathrm{CdSnSe}_{4}$

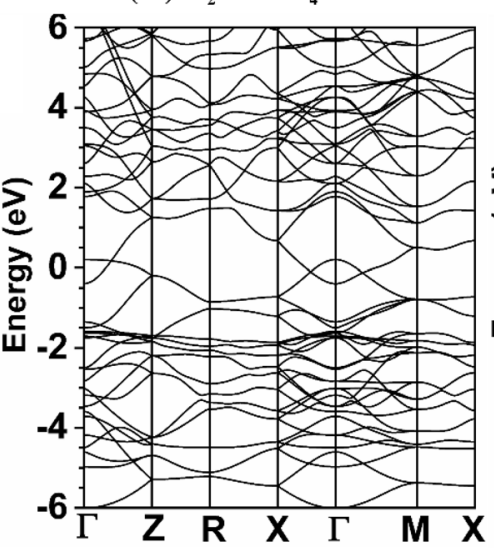

(76) $\mathrm{Ba}_{2} \mathrm{LuInSe}_{5}$

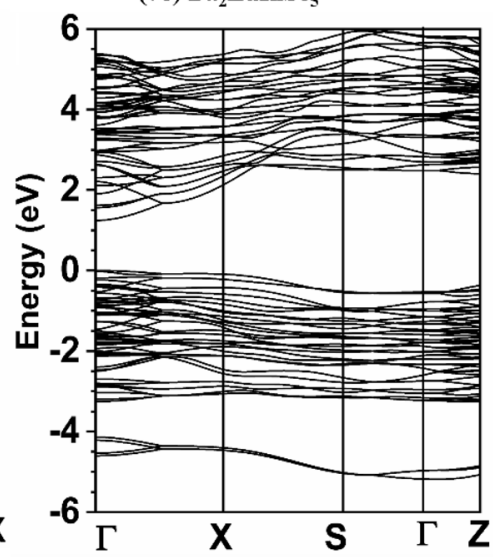

(97) $\mathrm{Tl}_{2} \mathrm{HgGeSe}_{4}$

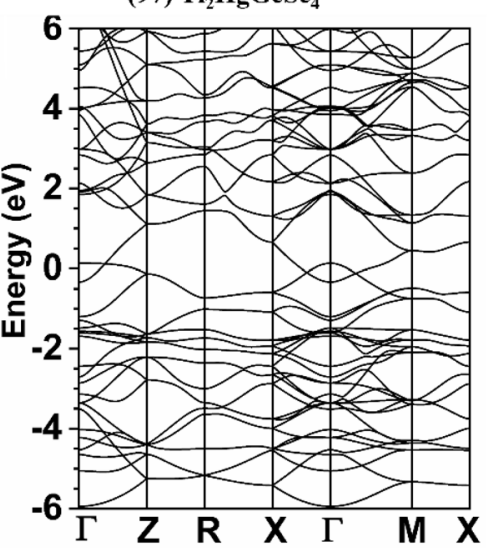

Figure 2. Calculated band structure of: $\mathrm{Ba}_{2} \mathrm{LaGaSe}_{5}, \mathrm{Ba}_{2} \mathrm{LuGaSe}_{5}, \mathrm{Ba}_{2} \mathrm{LuInSe}_{5}, \mathrm{Tl}_{2} \mathrm{CdGeSe}_{4}, \mathrm{Tl}_{2} \mathrm{CdSnSe}_{4}$, $\mathrm{Tl}_{2} \mathrm{HgGeSe}_{4}$, and $\mathrm{Tl}_{2} \mathrm{HgSnS}_{4}$.

related and Ag-related) indicated with horizontal bars in Fig. 5, while the second group $\left(A_{x} B_{y} C_{z} Q_{n}\right)$ with 45 crystals in Fig. 6 is divided into 9 subgroups indicated by horizontal bars which are related to the elements $A=$ $(\mathrm{Cu}, \mathrm{Ag}, \mathrm{Ba}, \mathrm{Cs}, \mathrm{K}, \mathrm{Li}, \mathrm{Lu}, \mathrm{Sr}, \mathrm{Tl})$ respectively. It can be seen that the first main group $\mathrm{A}_{2} \mathrm{BCQ}_{4}$ have relatively higher TBOD values than the second main group $\left(A_{x} B_{y} C_{z} Q_{n}\right)$. In Fig. 5 for the first main group, crystals with $A=$ $\mathrm{Cu}, \mathrm{Ag} ; \mathrm{B}=\mathrm{Hg} ; \mathrm{C}=\mathrm{Sn} ; \mathrm{Q}=\mathrm{Se}$, Te have the lowest TBOD. The data in Fig. 6 for the second group are more scattered. However, we can still observe that the $\mathrm{Cu}$-related crystals have the highest TBOD whereas the Ba-related crystals have the lowest TBOD. The Ag-related, Cs-related, and Li-related crystals all have very close TBOD values. An important observation from the TBOD calculations is that in moving from $S$ to Se to Te through these 99 crystals, the TBOD value decreases. The possible reason has to do with the size of the atoms which affects the volume of the crystal resulting in longer bond lengths hence smaller TBOD. That being said, we cannot say that the chalcogen elements completely control the TBOD value of the crystal because the elements A, B and to a lesser extend $\mathrm{C}$ also play a role in determining their total bond order and the volume of the crystal, hence the 
(10) $\mathrm{Cu}_{2} \mathrm{CdSiSe}_{4}$

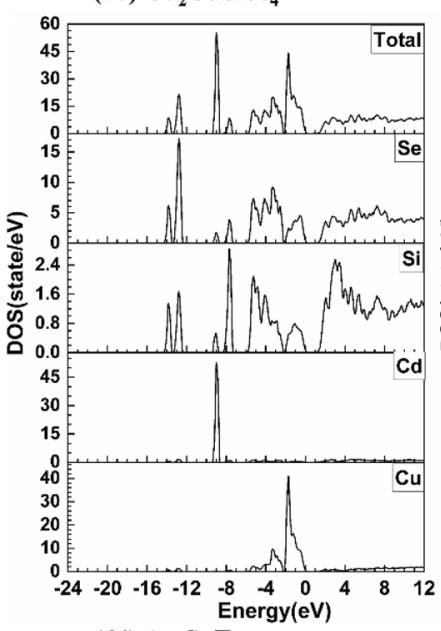

(64) $\mathrm{Ag}_{2} \mathrm{SnTe}_{3}$

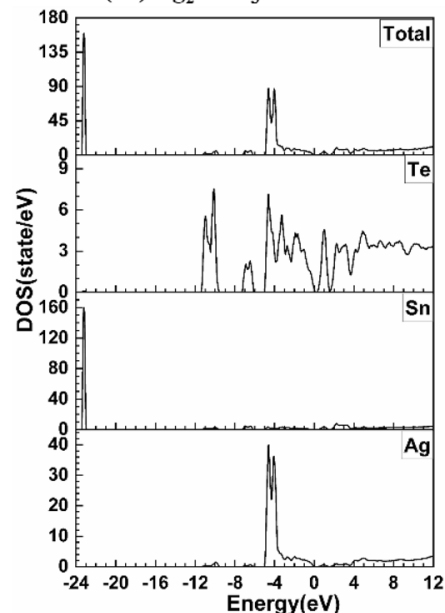

(74) $\mathrm{Ba}_{2} \mathrm{LaGaSe}_{5}$

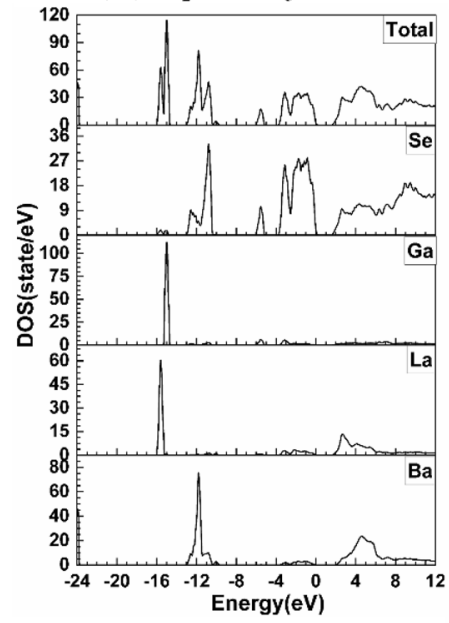

(16) $\mathrm{Cu}_{2} \mathrm{CdSnTe}_{4}$

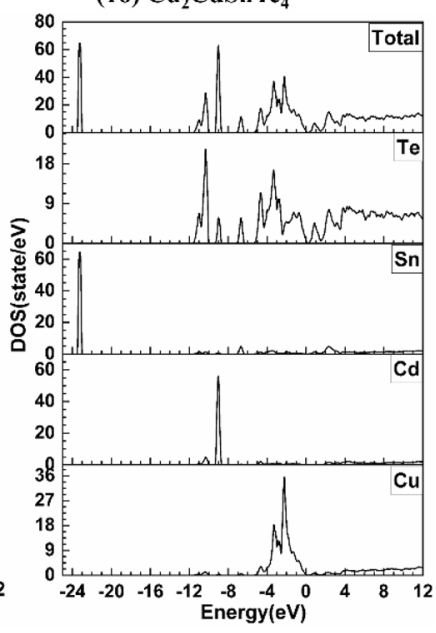

(66) $\mathrm{Ag}_{4} \mathrm{P}_{2} \mathrm{Se}_{6}$

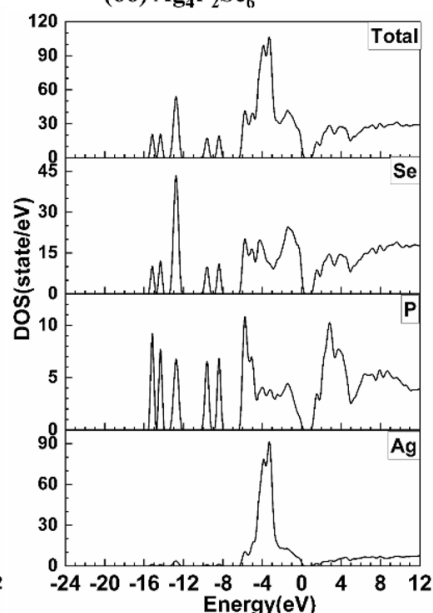

(75) $\mathrm{Ba}_{2} \mathrm{LuGaSe}_{5}$

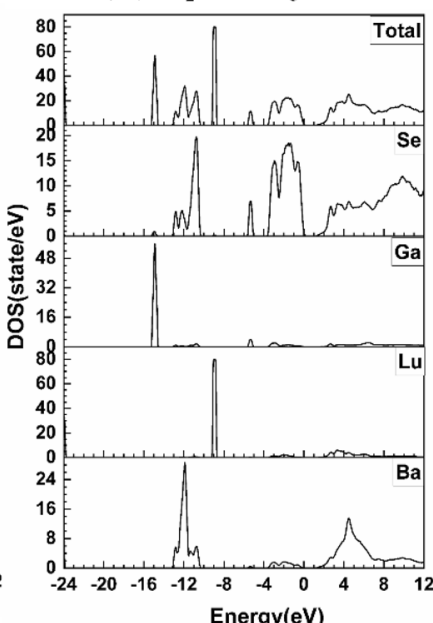

(37) $\mathrm{Cu}_{2} \mathrm{MgSnTe}_{4}$

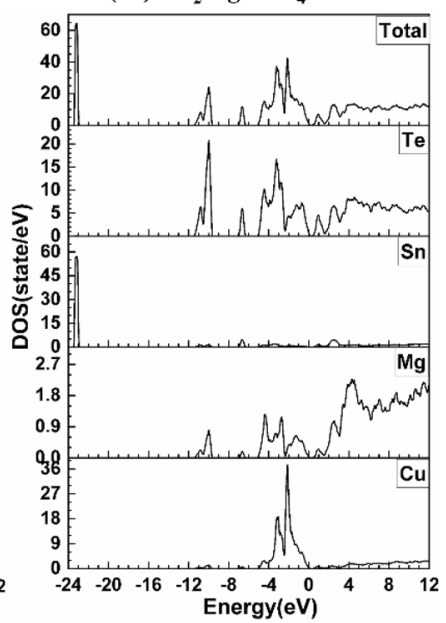

(69) $\mathrm{BaHg}_{2} \mathrm{As}_{2} \mathrm{~S}_{6}$

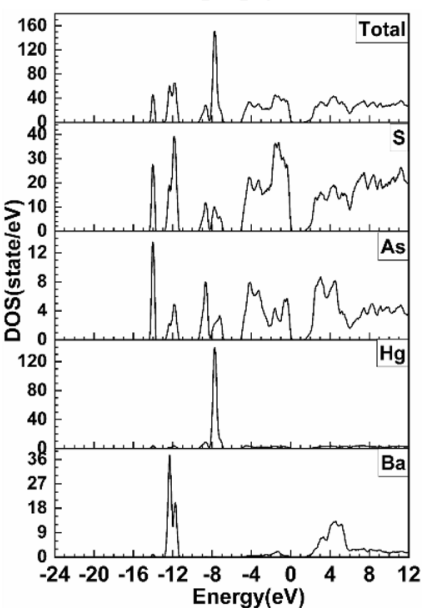

(76) $\mathrm{Ba}_{2} \mathrm{LuInSe}_{5}$

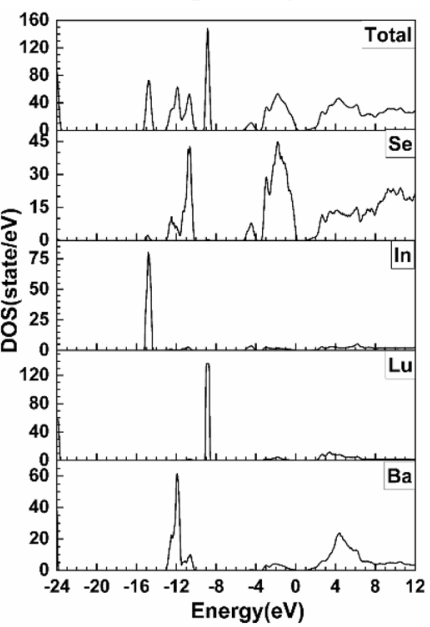

Figure 3. Calculated DOS and PDOS of: $\mathrm{Cu}_{2} \mathrm{CdSiSe}{ }_{4}, \mathrm{Cu}_{2} \mathrm{CdSnTe}{ }_{4}, \mathrm{Cu}_{2} \mathrm{MgSnTe}_{4}, \mathrm{Ag}_{2} \mathrm{SnTe}_{3}, \mathrm{Ag}_{4} \mathrm{P}_{2} \mathrm{Se}_{6}$, $\mathrm{BaHg}_{2} \mathrm{As}_{2} \mathrm{~S}_{6}, \mathrm{Ba}_{2} \mathrm{LaGaSe}_{5}, \mathrm{Ba}_{2} \mathrm{LuGaSe}_{5}, \mathrm{Ba}_{2} \mathrm{LuInSe}_{5}$.

TBOD. We need to reiterate that the use of the novel concept of TBOD is extremely helpful to extract the internal cohesion of otherwise very complex crystals of chalcogenide compounds.

Optical properties. The optical properties of these 99 chalcogenide crystals are particularly important because of their many optical applications. They can be calculated relatively easily within the one-electron random phase approximation using the OLCAO method. It starts with the calculations of the imaginary part of the 
(95) $\mathrm{Tl}_{2} \mathrm{CdGeSe}_{4}$

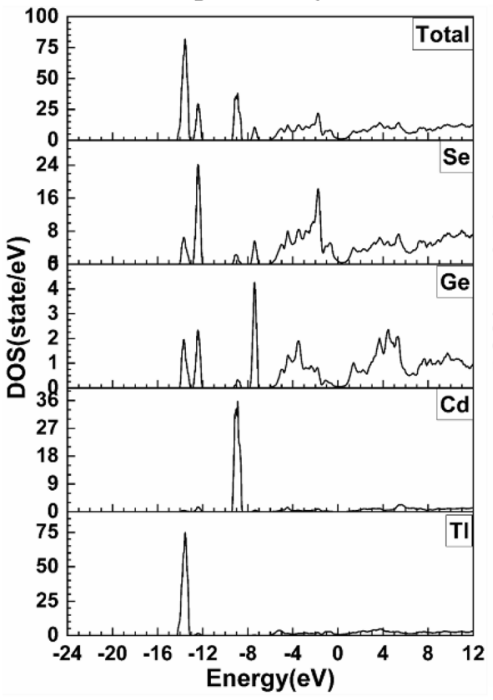

(99) $\mathrm{Tl}_{2} \mathrm{HgSnS}_{4}$

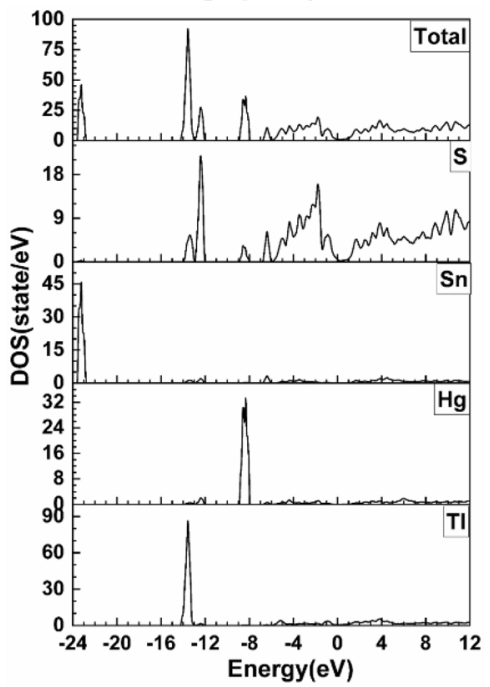

(96) $\mathrm{Tl}_{2} \mathrm{CdSnSe}_{4}$

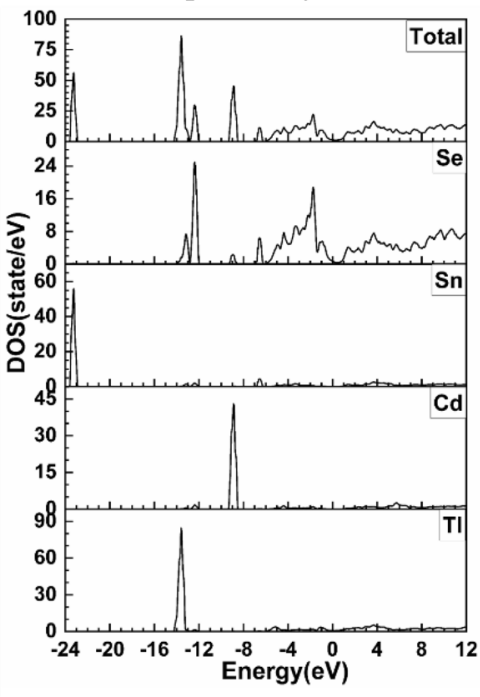

(97) $\mathrm{Tl}_{2} \mathrm{HgGeSe}_{4}$

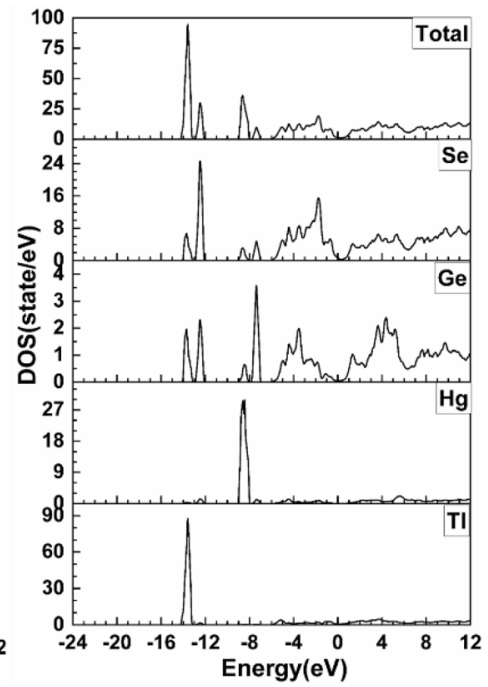

Figure 4. Calculated DOS and PDOS of $\mathrm{Tl}_{2} \mathrm{CdGeSe}_{4}, \mathrm{Tl}_{2} \mathrm{CdSnSe} \mathrm{Tl}_{4}, \mathrm{Tl}_{2} \mathrm{HgGeSe}_{4}$, and $\mathrm{Tl}_{2} \mathrm{HgSnS}_{4}$.

dielectric function $\epsilon_{2}(\omega)$ from the interband optical transition with explicit inclusion of the dipole matrix elements. The real part of the dielectric function $\epsilon_{1}(\omega)$ is obtained from $\epsilon_{2}(\omega)$ by applying Kramers-Kronig transformation. The refractive index $n$ of the crystal is obtained as the square root of $\epsilon_{1}(\omega)$ in the zero-frequency limit, or $n=\sqrt{\epsilon_{1}(0)}$. More details can be found in Sect. 1 in SI including the calculation of the energy loss function (ELF) and the evaluation of the Plasmon frequency $\omega_{p}$. The calculated real and imaginary parts of the dielectric functions for these 99 crystals are shown in Fig. S6, and the refractive indices $n$ are listed in Table S4. As can be seen, each crystal has its unique absorption features or interesting optical properties. We selectively discuss some of them in $\mathrm{A}_{2} \mathrm{BCQ}_{4}$ (with $\mathrm{A}=\mathrm{Ag}, \mathrm{Cu} ; \mathrm{B}=\mathrm{Sr}, \mathrm{Ba} ; \mathrm{C}=\mathrm{Ge}, \mathrm{Sn} ; \mathrm{Q}=\mathrm{S}$, Se) and also the following Ba-related and $\mathrm{Sr}$ related crystals $\left(71-\mathrm{Ba}_{2} \mathrm{AlSbS}_{5}, 72-\mathrm{Ba}_{2} \mathrm{GaBiSe}_{5}, 73-\mathrm{Ba}_{2} \mathrm{AsGaSe}_{5}, 74-\mathrm{Ba}_{2} \mathrm{LaGaSe}_{5}, 75-\mathrm{Ba}_{2} \mathrm{LuGaSe}_{5}, 76-\mathrm{Ba}_{2} \mathrm{LuInSe}_{5}\right.$, 77- $\mathrm{Ba}_{4} \mathrm{AgInS}_{6}, 86-\mathrm{SrCdGeS}_{4}, 87-\mathrm{SrCdGeSe}_{4}$ ). They are part of the results shown in Fig. S6. The general feature for these selected crystals is that $\epsilon_{1}(\omega)$ reaches a peak at certain energy and then starts decreasing, eventually reaching a negative value. It then increases again before finally leveling off to zero value again. Since the crossing at zero value is generally associated with Plasma excitation, this implies that in these group of selected crystal, they may have two plasma excitations and two Plasma frequencies, such as that reported recently in Ref. ${ }^{59}$. This unique feature is not specifically related to the structure of the crystals $\left(A_{2} B_{C Q}\right.$ or $\left.A_{x} B_{y} C_{z} Q_{n}\right)$, but strongly related to the presence of $\mathrm{Ba}$ and $\mathrm{Sr}$ in these crystals. This is an important observation revealed in the present study which clearly originate from the electronic structure. From the dielectric function, we can obtain the ELF for all the 99 chalcogenides which are shown in Fig. S7. The ELF is an important part of the optical properties of crystals and represents the collective excitation of excited electrons at high frequency. The position of its main peak is defined as the Plasmon frequency $\omega_{p}$ which usually occurs at the frequency when the real part of dielectric function vanishes. Below $\omega_{p}$, the incident waves will be mostly reflected. The $\omega_{p}$ values for the 99 


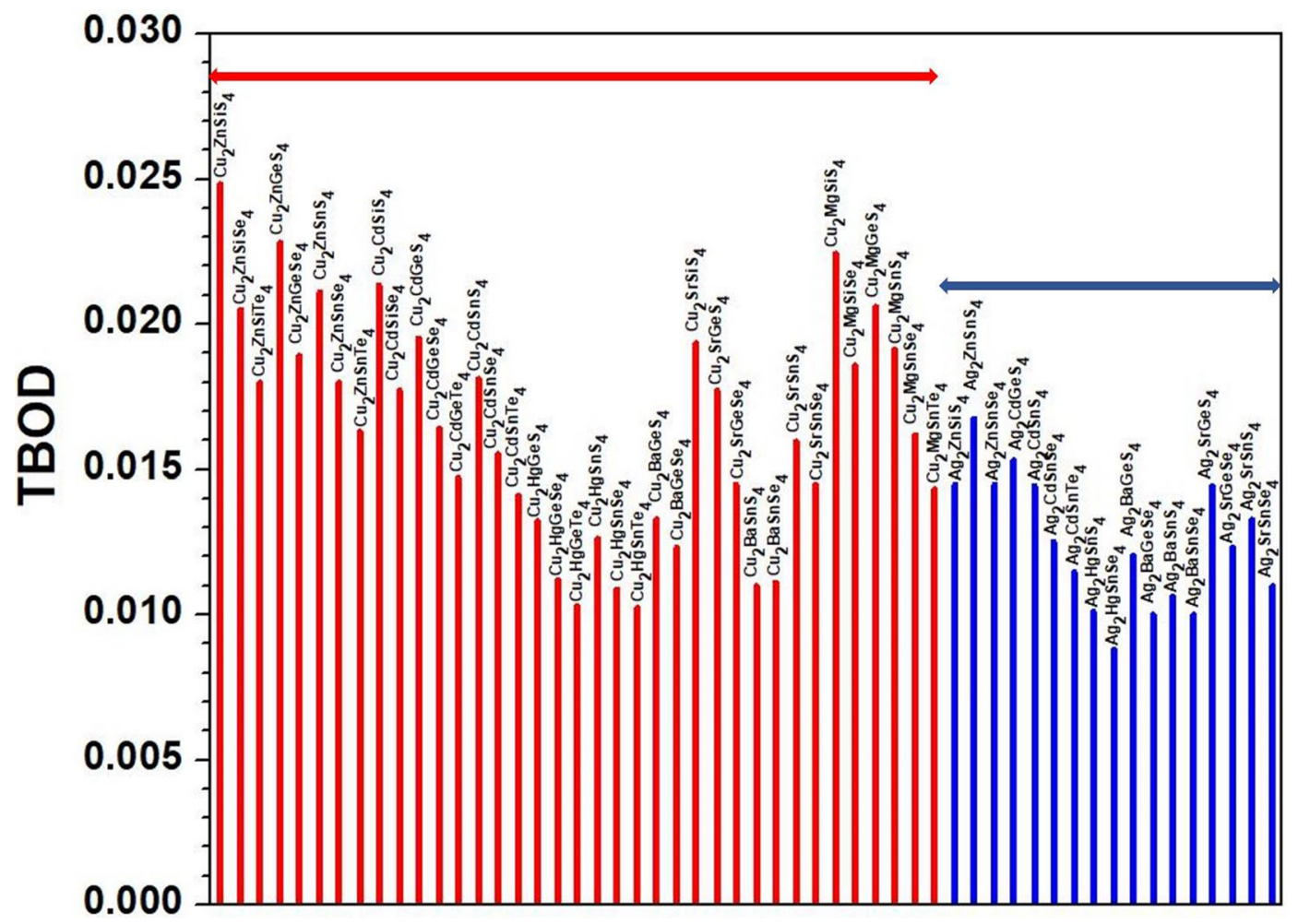

Figure 5. Distribution of the calculated TBOD for the 54 crystals (first group).

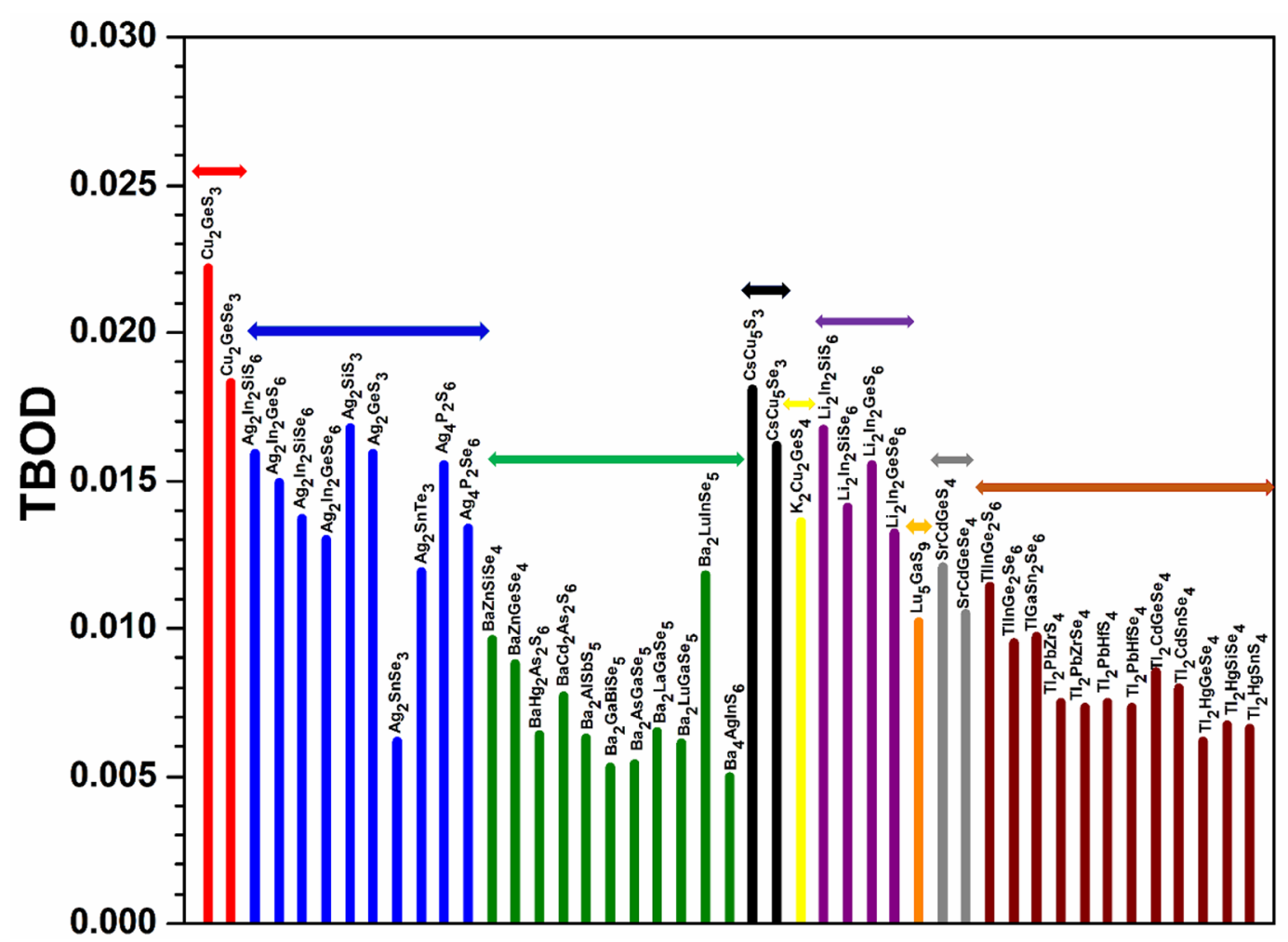

Figure 6. Distribution of the calculated TBOD for the 45 crystals (second group). 


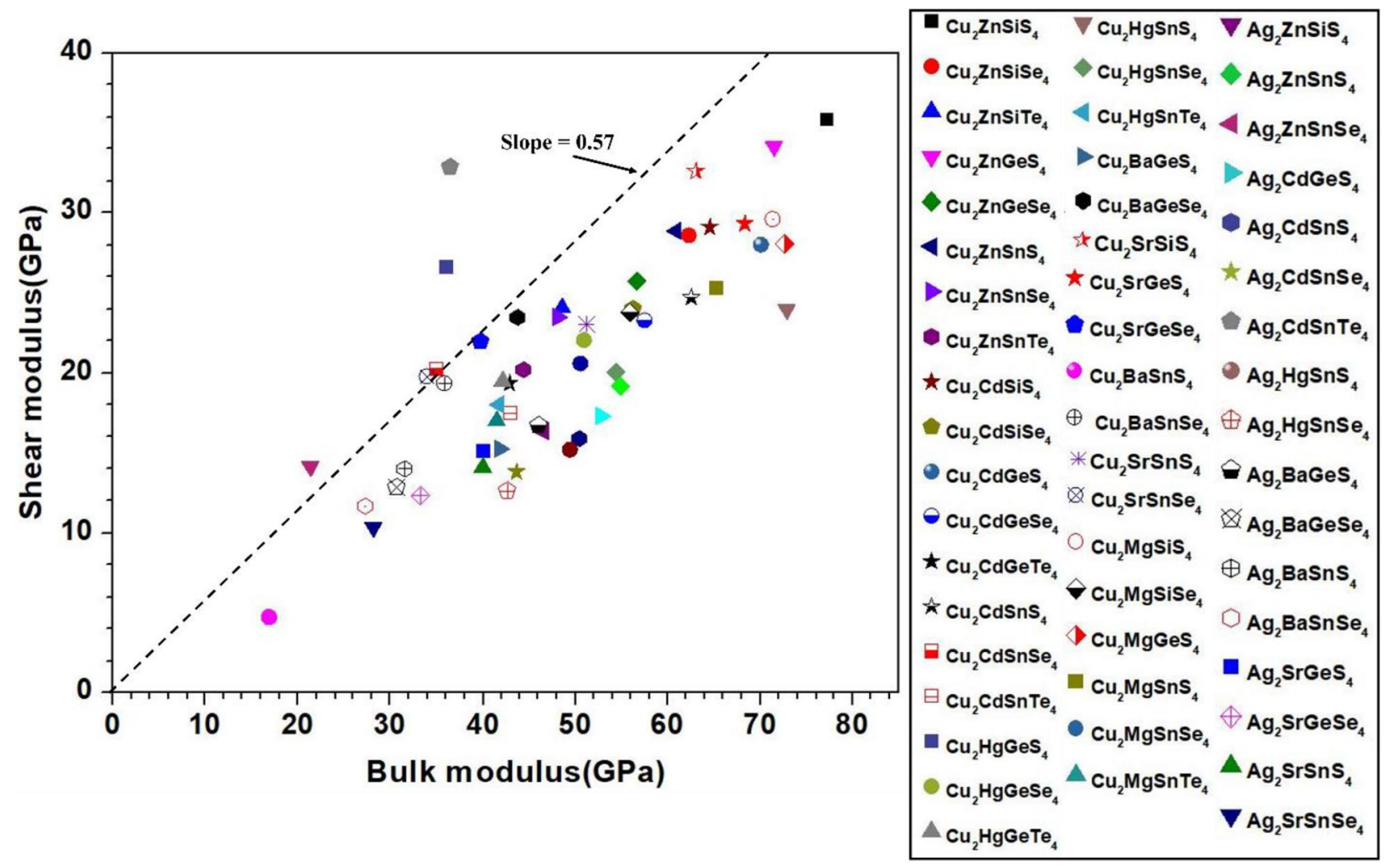

Figure 7. Bulk modulus versus shear modulus for the first group (54 crystals) of crystals.

crystals are listed in Table S3. The highest $\omega_{p}$ is identified to be in $85-\mathrm{Lu}_{5} \mathrm{GaS}_{9}$ at $31.10 \mathrm{eV}$, while the lowest $\omega_{p}$ is in $63-\mathrm{Ag}_{2} \mathrm{SnSe}_{3}$ at $15.50 \mathrm{eV}$.

Mechanical properties. Mechanical properties of chalcogenide materials are much less studied compared to optical properties even though they are critical in many practical applications ${ }^{60,61}$. In this work, we fill this void by calculating the mechanical properties of the 99 chalcogenides using the method described in Sect. 2 in SI. The calculated elastic constants are listed in Table S5 and the mechanical parameters derived from them are listed in Table S6. The principal coefficients $\mathrm{C}_{11}, \mathrm{C}_{22}$, and $\mathrm{C}_{33}$, related to the unidirectional compression along the principal $\mathrm{x}, \mathrm{y}$ and $\mathrm{z}$ directions, reflect the isotropic elasticity of the crystals and they are usually close in cubic crystals with high symmetry ${ }^{62}$. Equivalently, we say $\mathrm{C}_{11}, \mathrm{C}_{22}$, and $\mathrm{C}_{33}$ reflect the resistance to the deformation of the crystal along $\mathrm{x}, \mathrm{y}$, and $\mathrm{z}$ directions. The elastic constants depend on the crystals structure (lattice parameters) and the strength of the bonds between the elements in the crystal. Table S5 shows that some of the crystals have $\mathrm{C}_{22}$ higher than $\mathrm{C}_{11}$ and $\mathrm{C}_{33}$ which simply suggest that they are more compressible along $\mathrm{x}$ - and $\mathrm{z}$-axes than along $\mathrm{y}$-axis. We note that the two crystals $38-\mathrm{Ag}_{2} \mathrm{ZnSiS}$ and $63-\mathrm{Ag}_{2} \mathrm{SnSe}_{3}$ have negative elastic constants which implies a negative stiffness. This behavior could be related to a material instability ${ }^{63}$. To the best of our knowledge, this is the first time that this observation is reported for these two crystals either experimentally or computationally. From the elastic coefficient $\mathrm{Cij}$ and the compliance tensor $\mathrm{Sij}(\mathrm{Sij}=1 / \mathrm{Cij}$ ), the mechanical parameters bulk modulus (K), shear modulus $(\mathrm{G})$, Young's modulus (E), and Poisson's ratio $(\eta)$ can be obtained using VoigtReuss-Hill (VRH) approximation for polycrystals as explained in $\mathrm{SI}^{64-66}$. They are listed in Table S6. Another useful parameter is $\mathrm{G} / \mathrm{K}$ or Pugh's modulus ratio ${ }^{67,68}$. According to Pugh's criterion, crystals with G/K larger than 0.57 are brittle, and those with less than 0.57 tend to be more ductile ${ }^{68-71}$. Figure 7 shows the scattered plot of $\mathrm{G}$ versus $\mathrm{K}$ for the 54 crystals in the first main group, while Fig. 8 for the 45 crystals in the second main group. In both plots, we draw a dashed line with slope of 0.57 . For the first group, most crystals tend to be ductile except 44- $\mathrm{Ag}_{2} \mathrm{CdSnTe}{ }_{4}, 38-\mathrm{Ag}_{2} \mathrm{ZnSiS}_{4}$, and $17-\mathrm{Cu}_{2} \mathrm{HgGeS}_{4}$. In the second group, the data can be divided roughly into three subgroups. The first subgroup have $\mathrm{G} / \mathrm{K}$ values higher than $0.57\left(71-\mathrm{Ba}_{2} \mathrm{AlSbS}_{5}, 73-\mathrm{Ba}_{2} \mathrm{AsGaSe}_{5}, 75-\mathrm{Ba}_{2} \mathrm{Lu}-\right.$ $\mathrm{GaSe}_{5}, 80-\mathrm{K}_{2} \mathrm{Cu}_{2} \mathrm{GeS}_{4}, 81-\mathrm{Li}_{2} \mathrm{In}_{2} \mathrm{SiS}_{6}, 82-\mathrm{Li}_{2} \mathrm{In}_{2} \mathrm{SiSe}_{6}, 83-\mathrm{Li}_{2} \mathrm{In}_{2} \mathrm{GeS}_{6}, 84-\mathrm{Li}_{2} \mathrm{In}_{2} \mathrm{GeSe}_{6}, 85-\mathrm{Lu}_{5} \mathrm{GaS}_{9}, 88-\mathrm{TlInGe}_{2} \mathrm{~S}_{6}$, 90- $\mathrm{TlGaSn}_{2} \mathrm{Se}_{6}, 92-\mathrm{Tl}_{2} \mathrm{PbZrSe}_{4}$, and $94-\mathrm{Tl}_{2} \mathrm{PbHfSe}_{4}$ ) so they tend to be brittle. The second subgroup has data lie very close or on the dashed line (56- $\mathrm{Ag}_{2} \mathrm{In}_{2} \mathrm{GeS}_{6}, 57-\mathrm{Ag}_{2} \mathrm{In}_{2} \mathrm{SiSe}_{6}, 58-\mathrm{Ag}_{2} \mathrm{In}_{2} \mathrm{GeSe}_{6}, 67-\mathrm{BaZnSiSe}_{4}, 68-\mathrm{BaZnGeSe}_{4}$, 72- $\mathrm{Ba}_{2} \mathrm{GaBiSe}_{5}, 74-\mathrm{Ba}_{2} \mathrm{LaGaSe}_{5}, 76-\mathrm{Ba}_{2} \mathrm{LuInSe}_{5}, 77-\mathrm{Ba}_{4} \mathrm{AgInS}_{6}, 86-\mathrm{SrCdGeS}_{4}, 87-\mathrm{SrCdGeSe}_{4}, 89-\mathrm{TlInGe}_{2} \mathrm{Se}_{6}$, 91- $\mathrm{Tl}_{2} \mathrm{PbZrS}_{4}$, and $93-\mathrm{Tl}_{2} \mathrm{PbHfS}_{4}$ ). In the third subgroup, the remaining 18 data points are located under the dashed line, so these crystals tend to be more ductile.

To explore the correlation in the mechanical properties of these 99 chalcogenides in more detail, the histogram plots of K in Figs. 9 and 10 divided into 2 main groups similar to Fig. 5 for the TBOD. Similar plots for the $\mathrm{G}$ in the 2 main groups are displayed in Figs. 11 and 12. The Cu-related crystals have higher bulk and shear modulus than the Ag-related crystals on average, while the data in the nine subgroups of the second main 


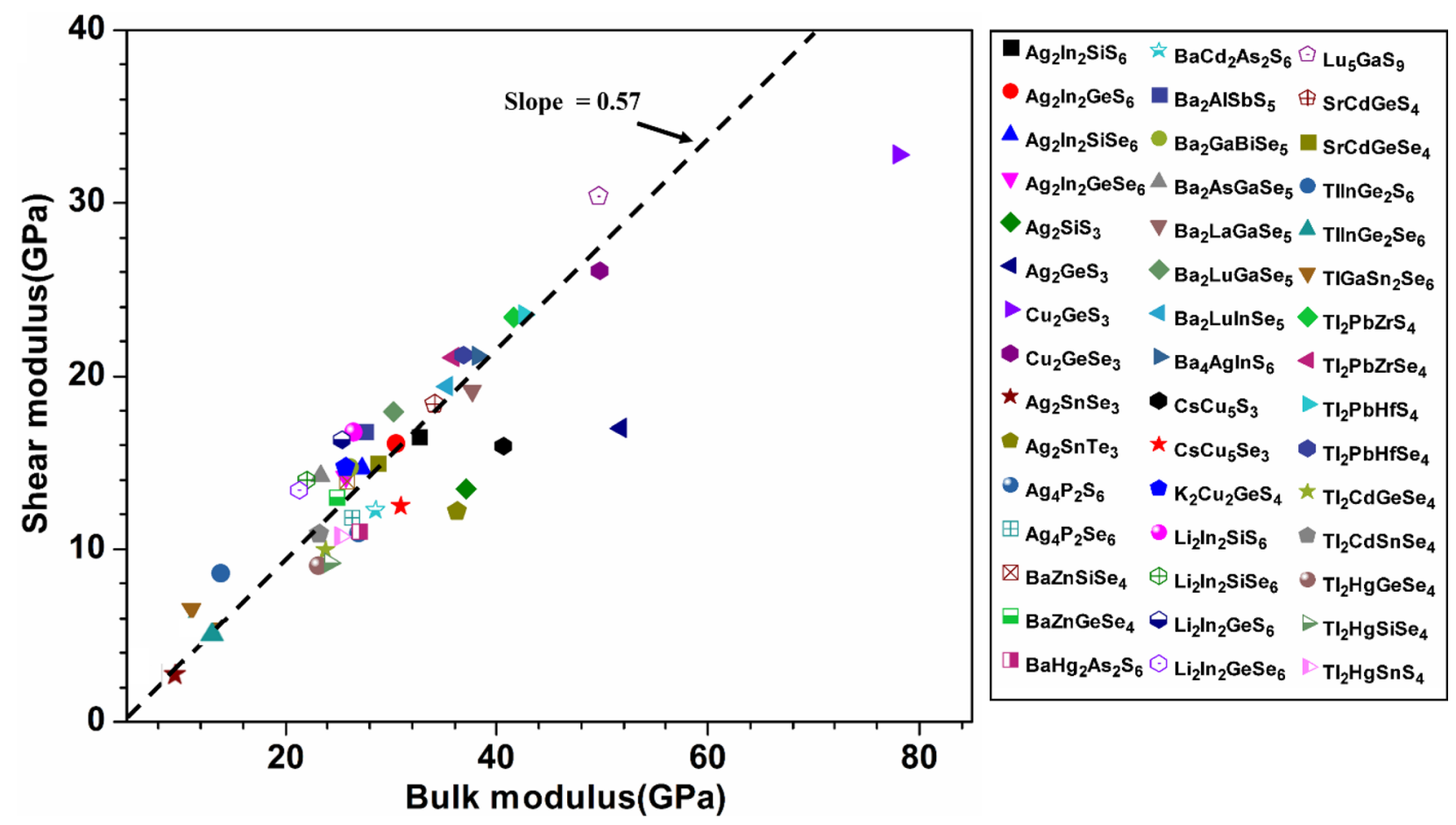

Figure 8. Bulk modulus versus shear modulus for the second group (45 crystals) of crystals.

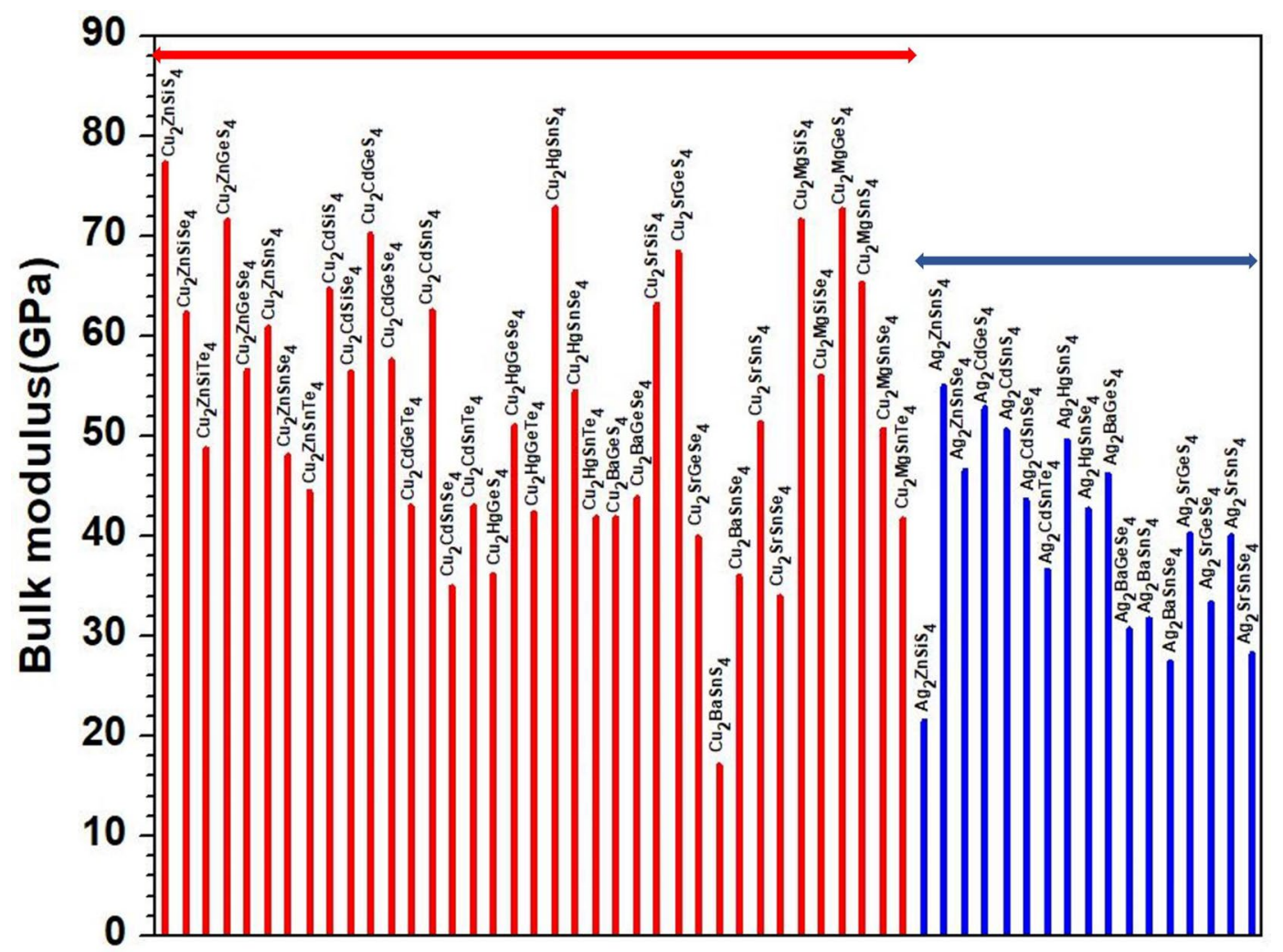

Figure 9. Distribution of bulk modulus for the first group (54 crystals). 


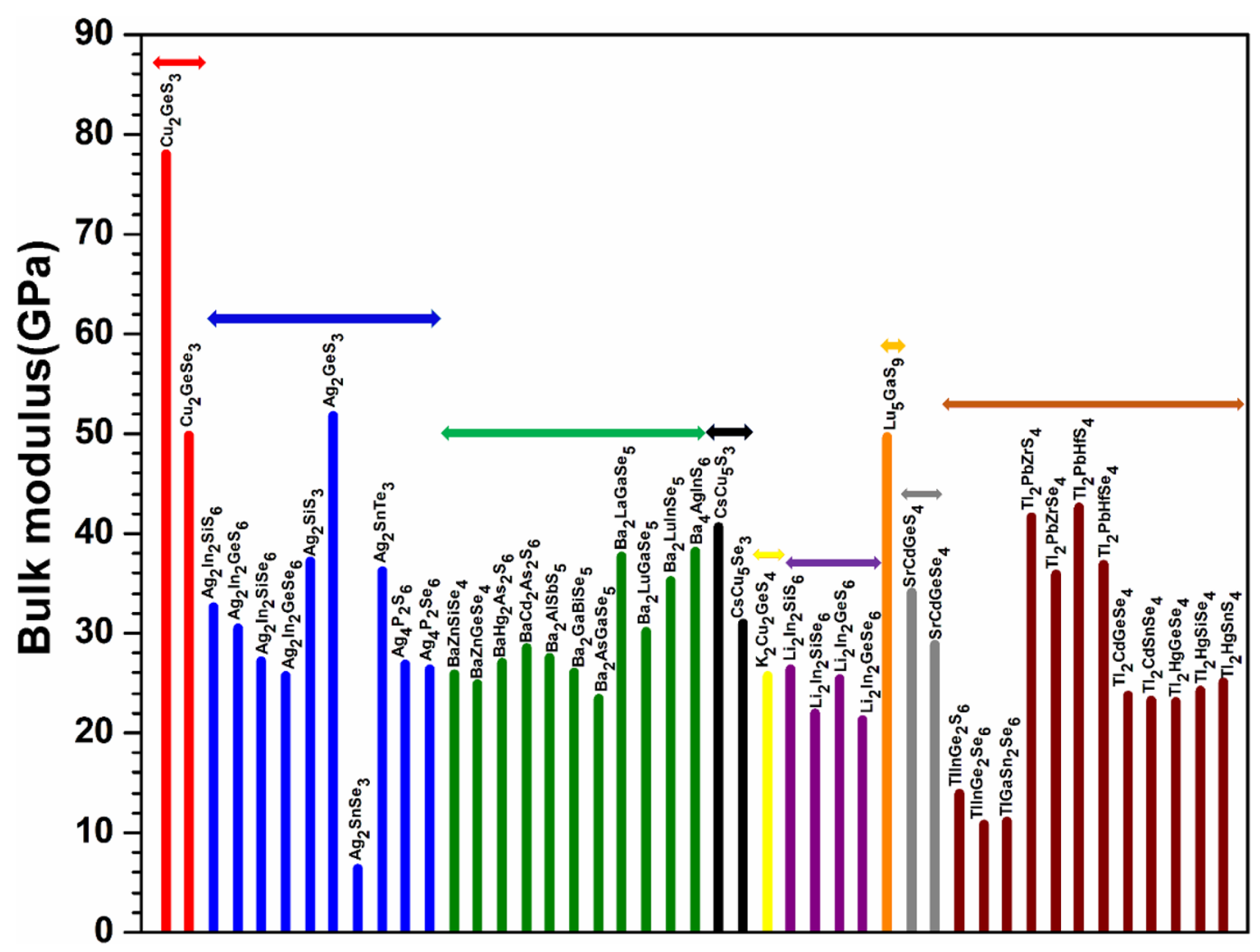

Figure 10. Distribution of bulk modulus for the second group (45 crystals).

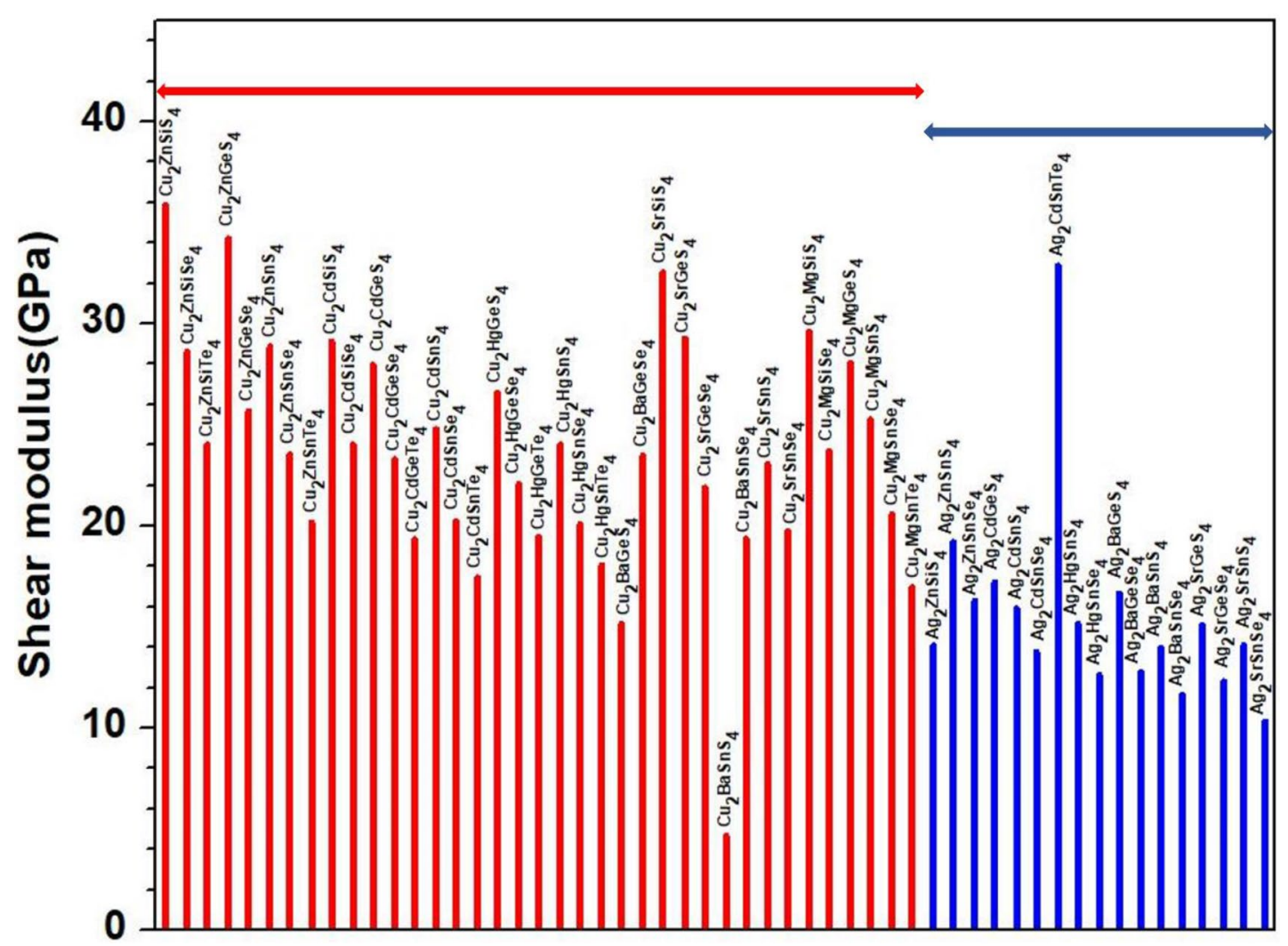

Figure 11. Distribution of shear modulus for the first group (54 crystals). 


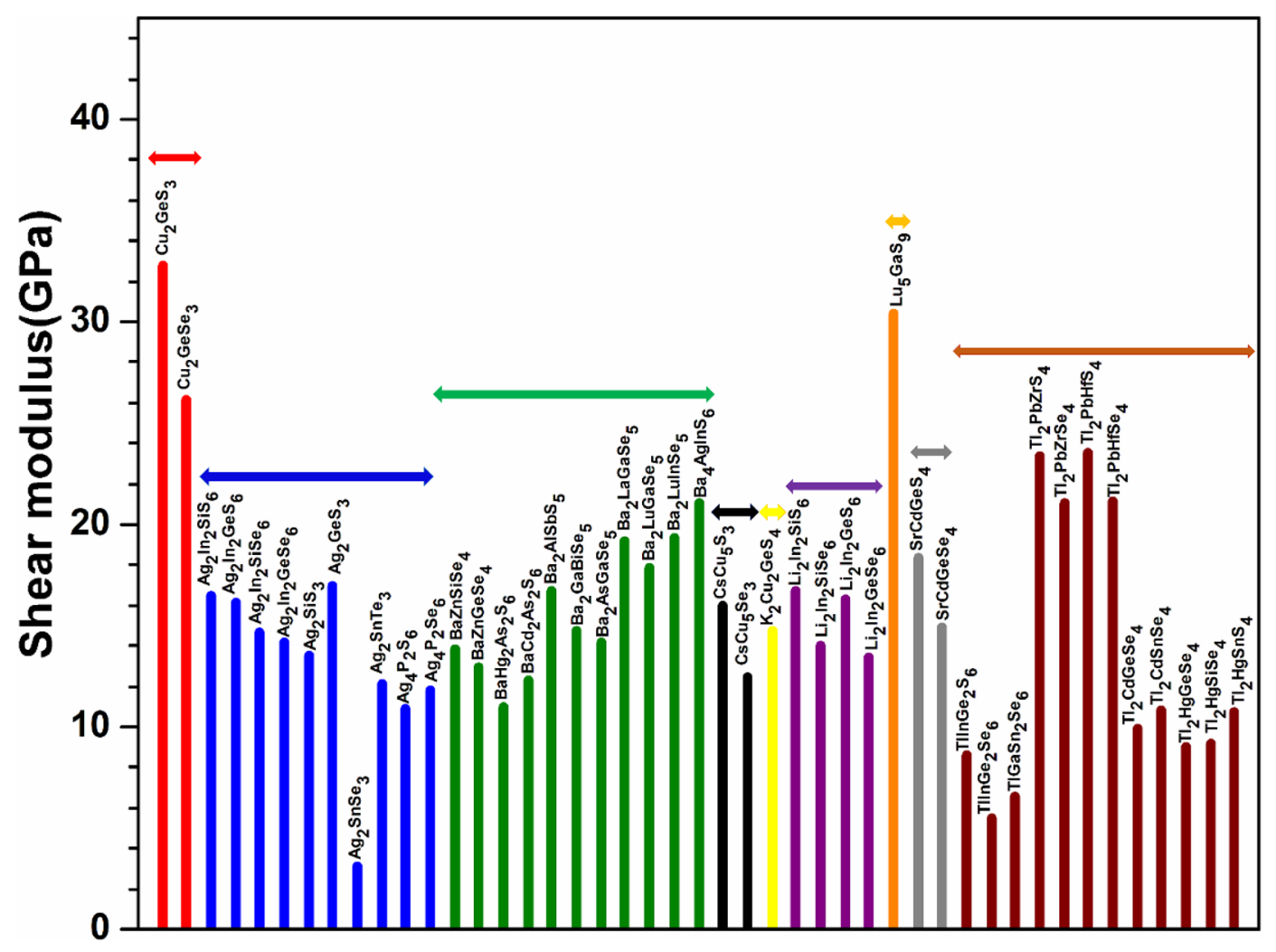

Figure 12. Distribution of shear modulus for the second group (45 crystals).

group crystals are again rather scattered. Still, we can note that $\mathrm{Cu}$ and Lu related crystals have high $\mathrm{G}$ and $\mathrm{K}$, and some of the $\mathrm{Tl}$ related crystals have lowest values, with $\mathrm{Ag}, \mathrm{Ba}, \mathrm{Li}, \mathrm{K}$ related crystals have intermediate and comparable values. Also, the first main group have higher $\mathrm{K}$ and $\mathrm{G}$ values than the second main group crystals. We also notice that $\mathrm{K}$ and $\mathrm{G}$ values decrease in moving from $\mathrm{S}$ to $\mathrm{Se}$ to Te. This feature can again be attributed to the larger size of Te atom resulting in weaker bond strength and more brittle crystals. The same feature has been observed for the TBOD and this implies a strong correlation between the mechanical properties and TBOD. Figures 13 and 14 show the scattered plots of TBOD versus Poisson's ratio $\eta$ to explore any trend for these 99 crystals in two groups. It appears that the relationship between TBOD and Poisson's ratio is not that much easy to explain and the data are scattered. In a broader scale, we can still observe a general trend that a larger TBOD implies a larger Poisson's ratio.

Identification of the underlying correlation between the electronic structure and the bonding characteristics of the chalcogenide crystals is one of the main objectives in this work. In this regard, exploring the connection between mechanical properties of these 99 crystals and the TBOD could be revealing. In Figs. 15, 16, 17, and 18, we plot the bulk modulus and shear modulus versus TBOD for the 99 crystals in the two separate groups. For the first main group of 54 crystals, there is a very clear correlation between the two moduli $(K, G)$ and the TBOD. $\mathrm{K}$ and $\mathrm{G}$ increase linearly with the TBOD with only a few outliers. For the second main group of 45 crystals, the situation is slightly different. Moreover, we divided the crystals in this main group into two subgroups. In the first subgroup (71- $\mathrm{Ba}_{2} \mathrm{AlSbS}_{5}, 72-\mathrm{Ba}_{2} \mathrm{GaBiSe}_{5}, 73-\mathrm{Ba}_{2} \mathrm{AsGaSe}_{5}, 74-\mathrm{Ba}_{2} \mathrm{LaGaSe}_{5}, 75-\mathrm{Ba}_{2} \mathrm{LuGaSe}_{5}, 77-\mathrm{Ba}_{4} \mathrm{AgInS}_{6}$, 91- $\mathrm{Tl}_{2} \mathrm{PbZrS}_{4}, 92-\mathrm{Tl}_{2} \mathrm{PbZrSe}_{4}, 93-\mathrm{Tl}_{2} \mathrm{PbHfS}_{4}, 94-\mathrm{Tl}_{2} \mathrm{PbHfSe}_{4}-$ mostly contains the Ba-related and some of the Tlrelated crystals inside the blue circle), they are quite scattered with no clear correlation for $\mathrm{K}$ and $\mathrm{G}$ with TBOD. While in the second subgroup (the remaining crystals), there is a reasonable correlation with $\mathrm{K}$ and $\mathrm{G}$ steadily increasing linearly with TBOD. The crystal $85-\mathrm{Lu}_{5} \mathrm{GaS}_{9}$ deviates from this behavior. It exhibits a sharp increase of $\mathrm{G}$ and $\mathrm{K}$ with TBOD. We conclude that the mechanical properties of these 99 chalcogenides are strongly related to the strength of the interatomic bonds which are collectively represented by the single matric TBOD.

\section{Conclusion}

In conclusion, a comprehensive library of the electronic structure, interatomic bonding, optical, and mechanical properties of the 99 chalcogenides was assembled on the basis of extensive first-principles calculations. We summarize below the new insights obtained and the conclusions reached in this study by using the same approach and resulting in a pronounced consistency of the result.

1. Most of these chalcogenide crystals are semiconductors with small band gaps with few of them are semimetals. The reported results for $10-\mathrm{Cu}_{2} \mathrm{CdSiSe} e_{4}, 16-\mathrm{Cu}_{2} \mathrm{CdSnTe}{ }_{4}, 37-\mathrm{Cu}_{2} \mathrm{MgSnTe}_{4}, 64-\mathrm{Ag}_{2} \mathrm{SnTe}_{3}, 66-\mathrm{Ag}_{4} \mathrm{P}_{2} \mathrm{Se}_{6}$, 


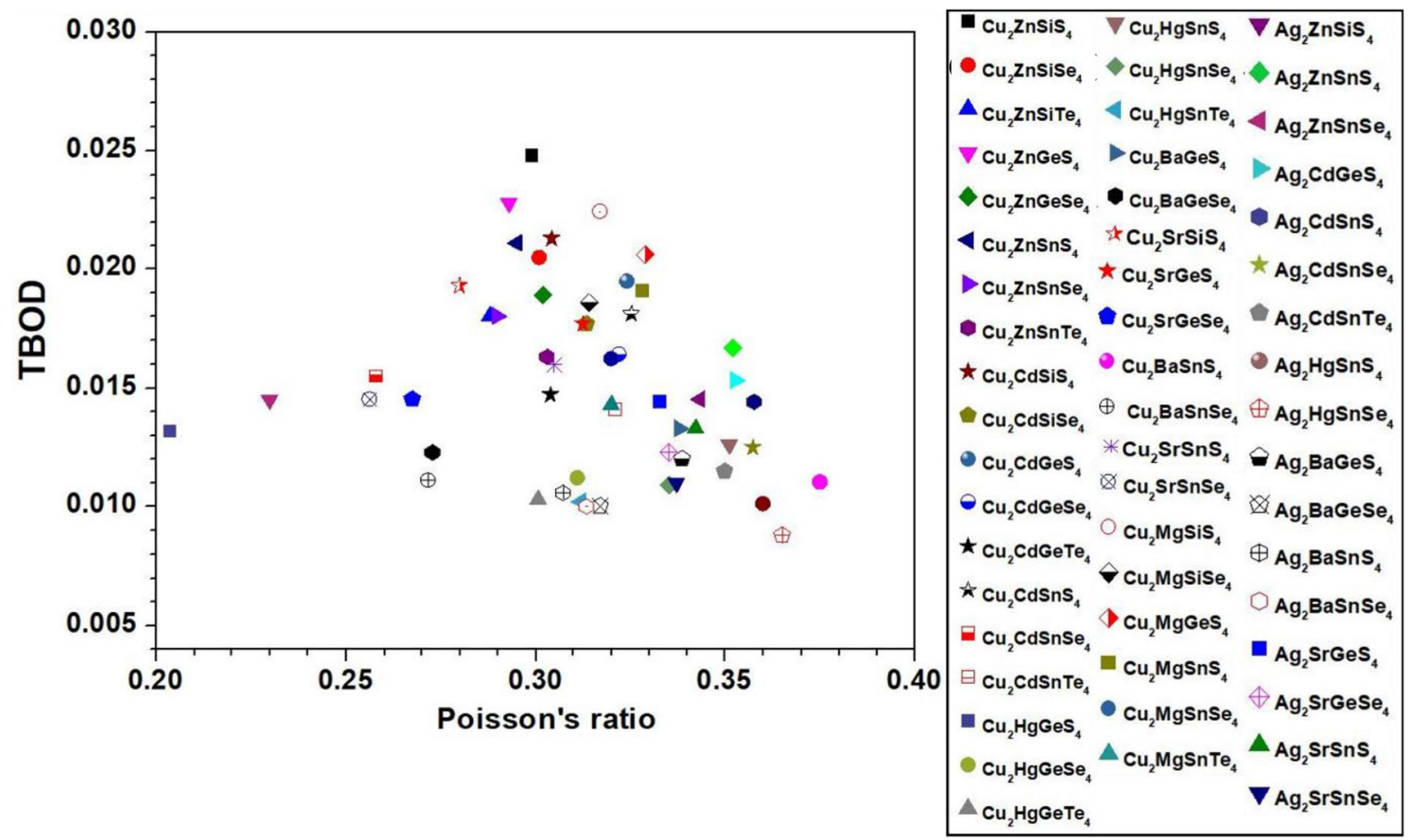

Figure 13. TBOD versus Poisson's ratio for the first group (54 crystals) of crystals.

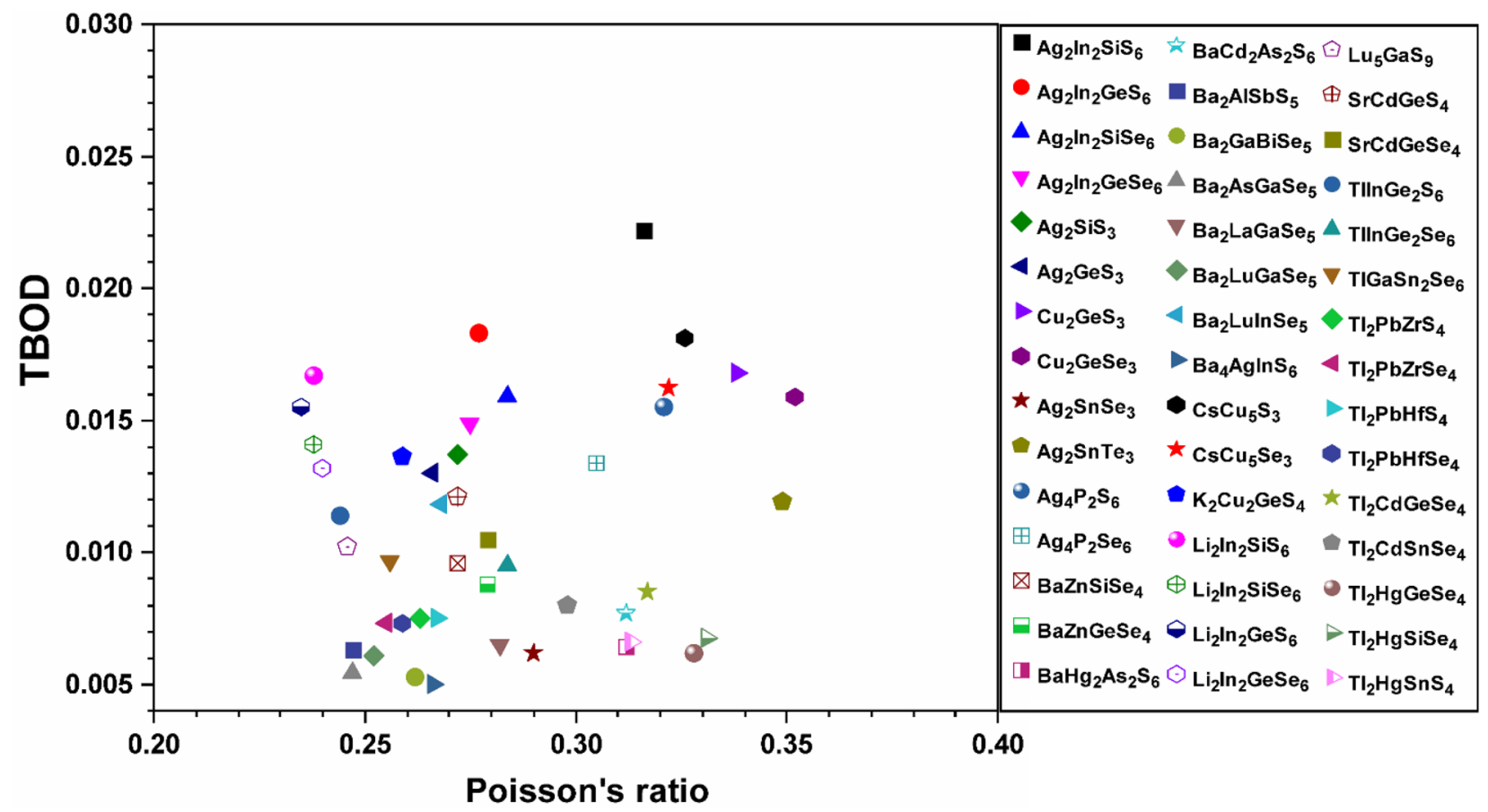

Figure 14. TBOD versus Poisson's ratio for the second group ( 45 crystals) of crystals.

69- $\mathrm{BaHg}_{2} \mathrm{As}_{2} \mathrm{~S}_{6}, 74-\mathrm{Ba}_{2} \mathrm{LaGaSe}_{5}, 75-\mathrm{Ba}_{2} \mathrm{LuGaSe}_{5}, 76-\mathrm{Ba}_{2} \mathrm{LuInSe}_{5}, 95-\mathrm{Tl}_{2} \mathrm{CdGeSe}_{4}, 96-\mathrm{Tl}_{2} \mathrm{CdSnSe} \mathrm{C}_{4}, 97-\mathrm{Tl}{ }_{2} \mathrm{Hg}-$ $\mathrm{GeSe}_{4}$, and $99-\mathrm{Tl}_{2} \mathrm{HgSnS}_{4}$ crystals are new theoretical prediction.

2. Several of these crystals have very small energy gaps of about $0.005-0.235 \mathrm{eV}$ including $18-\mathrm{Cu}_{2} \mathrm{HgGeSe}_{4}$, $5-\mathrm{Cu}_{2} \mathrm{ZnGeSe}_{4}, 12-\mathrm{Cu}_{2} \mathrm{CdGeSe}_{4}, 13-\mathrm{Cu}_{2} \mathrm{CdGeTe}_{4}, 15-\mathrm{Cu}_{2} \mathrm{CdSnSe}{ }_{4}, 19-\mathrm{Cu}_{2} \mathrm{HgGeTe}_{4}, 20-\mathrm{Cu}_{2} \mathrm{HgSnS}_{4}$, 61- $\mathrm{Cu}_{2} \mathrm{GeS}_{3}, 79-\mathrm{CsCu}_{5} \mathrm{Se}_{3}$. 


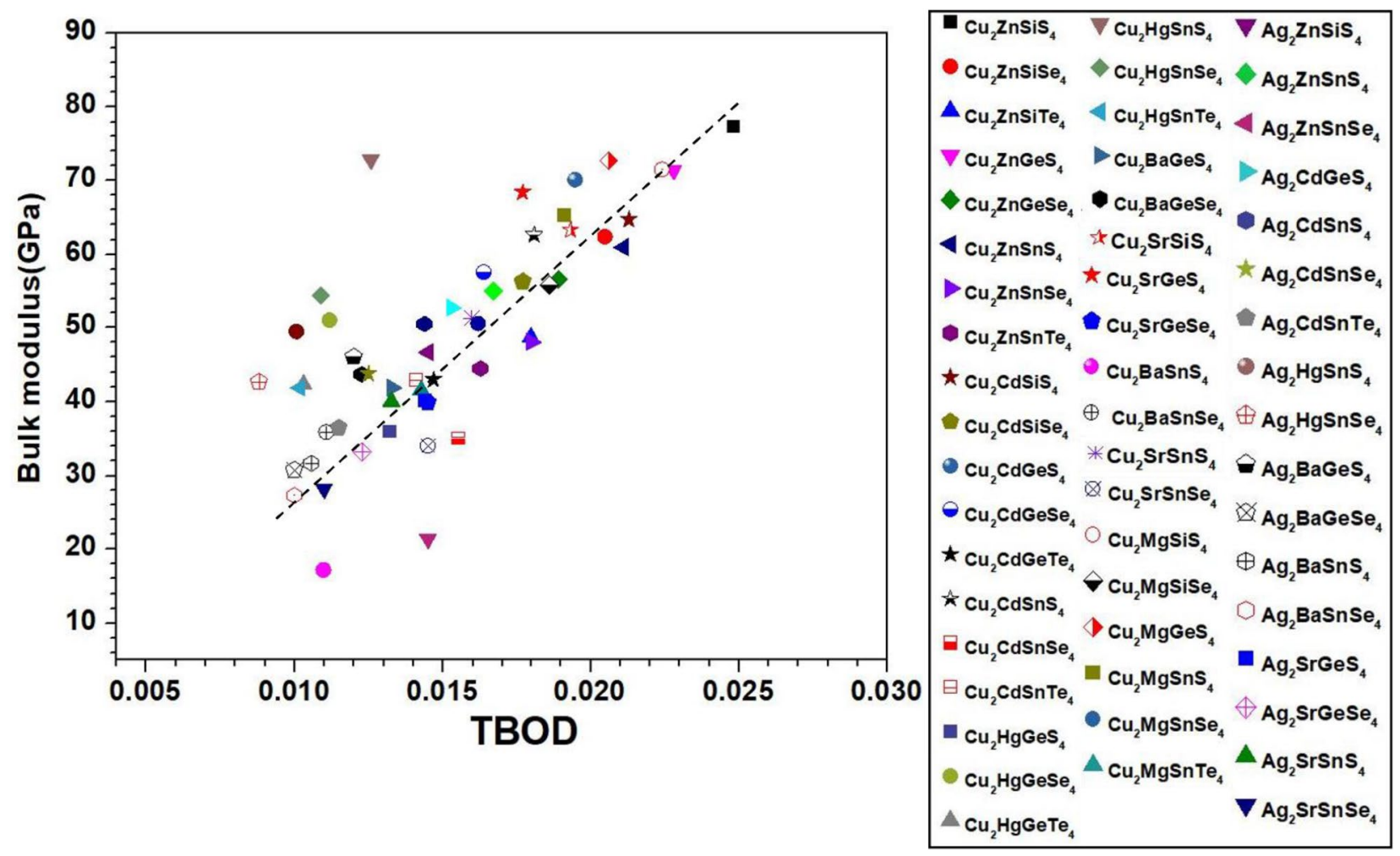

Figure 15. Bulk modulus versus TBOD for the first group (the 54 chalcogenide crystals).

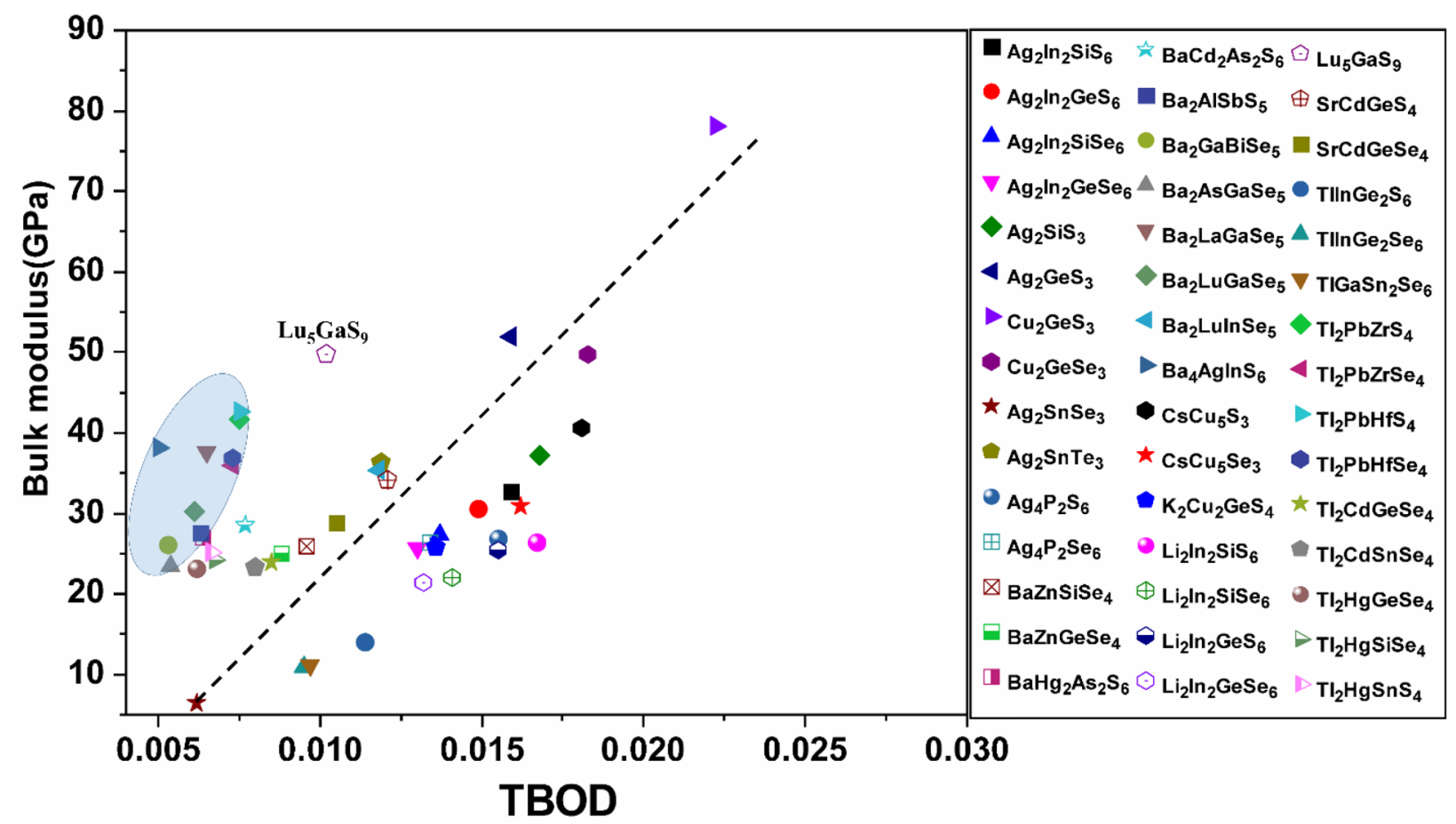

Figure 16. Bulk modulus versus TBOD for the second group (the 45 chalcogenide crystals).

3. Analysis of the atomic partial charges shows $\mathrm{Cu}$ and $\mathrm{Ag}$ atoms are electronegative in some crystals, especially in the ones that contains Se and Te. This new finding is consistent with our recent work on other 32 simpler chalcogenide crystals.

4. In the first main group of crystals, the crystals $A_{2} B_{C Q}$ with $A=C u ; B=Z n, M g ; C=S i, G e ; Q=S$ ) have the highest TBOD, while the crystals $\mathrm{A}_{2} \mathrm{BCQ}_{4}$ (with $\mathrm{A}=\mathrm{Cu}, \mathrm{Ag} ; \mathrm{B}=\mathrm{Hg} ; \mathrm{C}=\mathrm{Sn} ; \mathrm{Q}=\mathrm{Se}, \mathrm{Te}$ ) have the lowest 


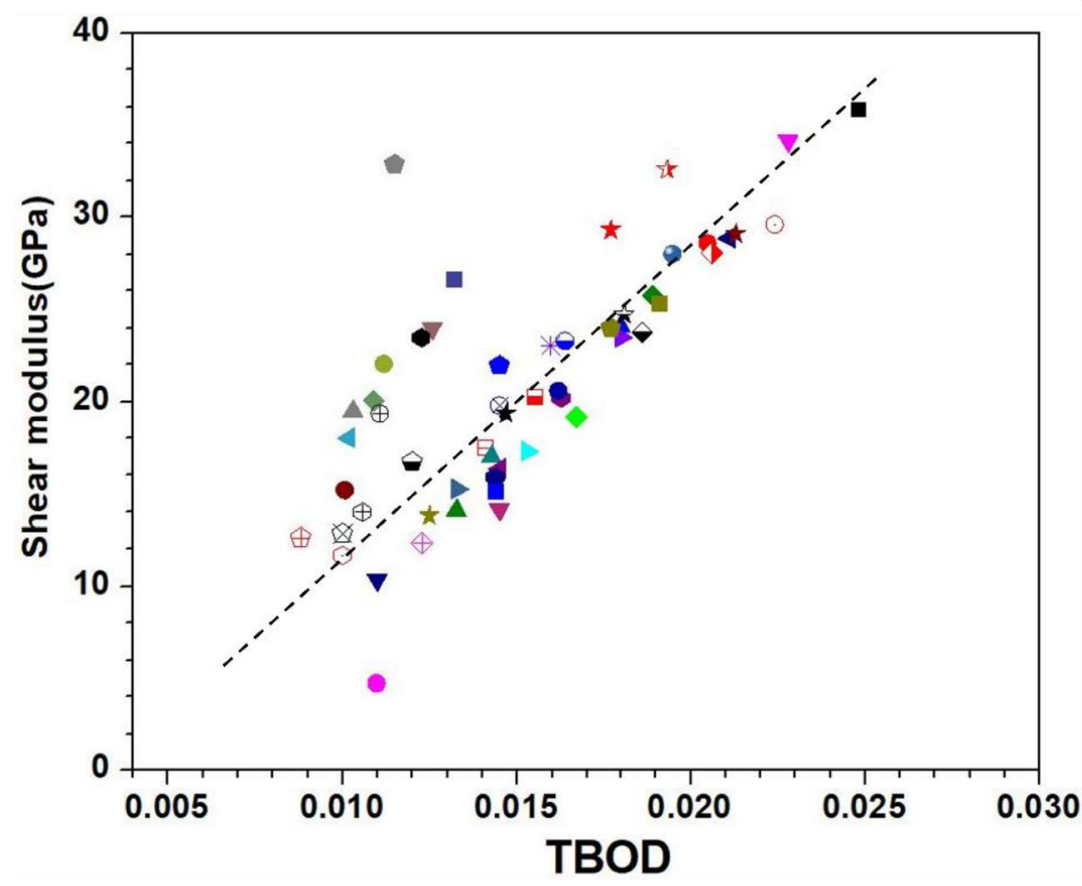

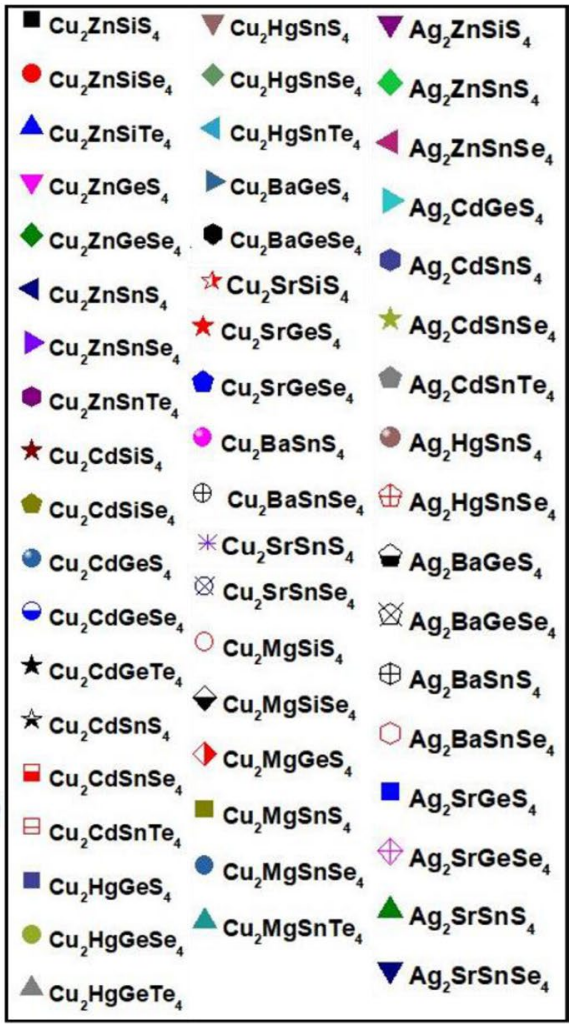

Figure 17. Shear modulus versus TBOD for the first group (the 54 chalcogenide crystals).

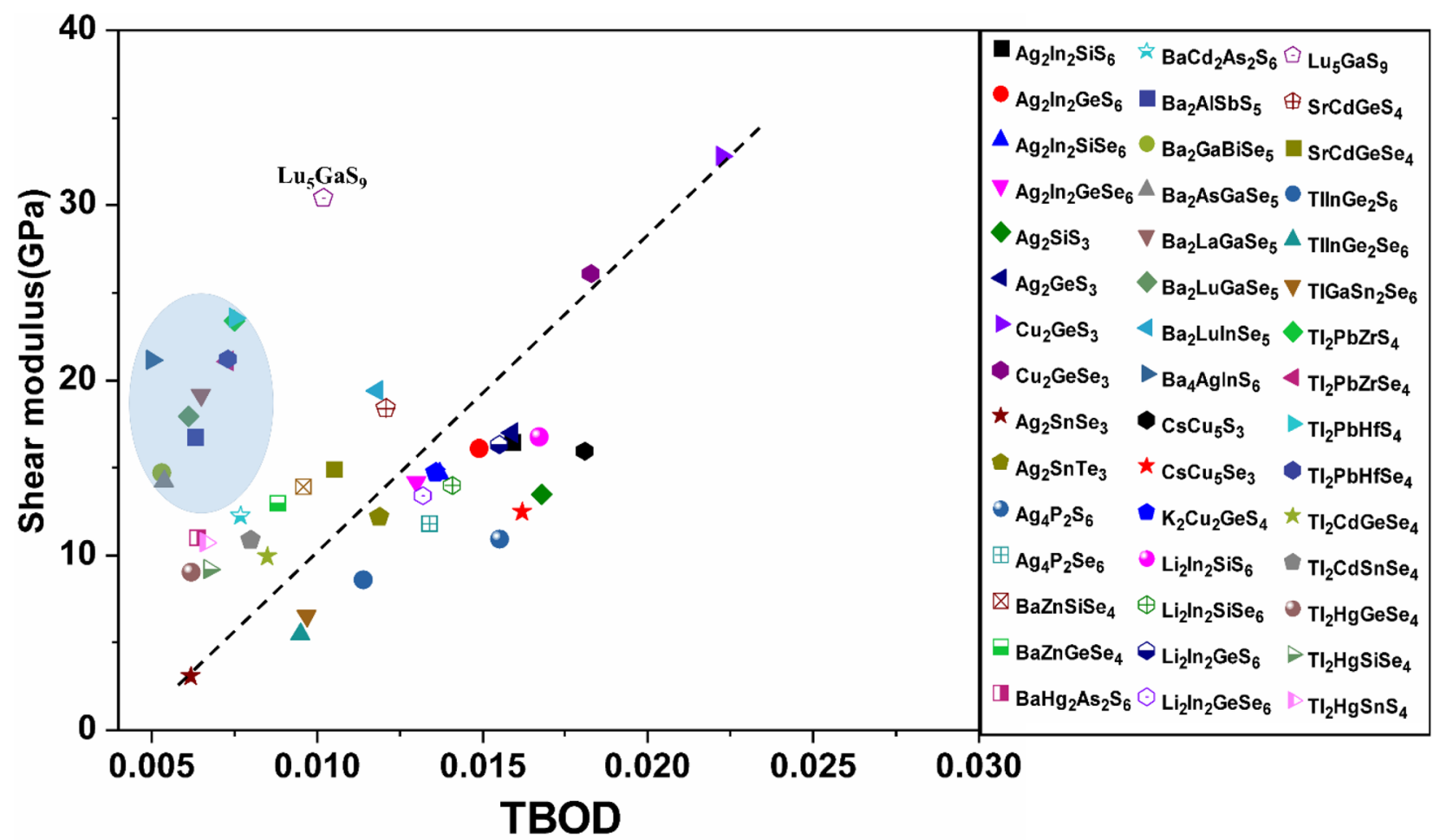

Figure 18. Shear modulus versus TBOD for the second group (the 45 chalcogenide crystals). 
TBOD. In the second main group, the $\mathrm{Cu}$, Cs-related crystals have the highest TBOD and the Ba-related crystals have the lowest TBOD. The Ag-related, Cs-related and Li-related crystals have very similar TBOD.

5. The optical spectra of the 99 crystals are calculated within the random phase approximation. They have medium values for the refractive index $\mathrm{n}$ in the range of 4.424-4.524.

6. The mechanical properties for these 99 crystals show large variations between the two main groups $\left(\mathrm{A}_{2} \mathrm{BCQ}_{4}\right)$ and $\left(A_{x} B_{y} C_{z} Q_{n}\right)$. The first group crystals tend to be more ductile than those from the second group. They are both reasonably correlated with the TBOD. The results and correlations summarized above can facilitate the design of new chalcogenide crystals and glasses for potential novel applications. They constitute a formidable database for complex chalcogenide crystals that was not available before. We believe that the present work can facilitate the discovery and production of good-quality chalcogenides with a variety of energy or environmental applications.

\section{Data availability}

All the data in this paper including those in the supplementary materials are freely available by contacting the one of the corresponding authors (chingw@umkc.edu)

Received: 21 November 2020; Accepted: 6 April 2021

Published online: 10 May 2021

\section{References}

1. Fujishima, A. \& Honda, K. Electrochemical photolysis of water at a semiconductor electrode. Nature 238, 37-38 (1972).

2. Kolpak, A. M. \& Grossman, J. C. Azobenzene-functionalized carbon nanotubes as high-energy density solar thermal fuels. Nano Lett. 11, 3156-3162 (2011).

3. Guo, Q. et al. Fabrication of 7.2 cztsse solar cells using czts nanocrystals. J. Am. Chem. Soc. 132, 17384-17386 (2010).

4. Katagiri, H. et al. Development of czts-based thin film solar cells. Thin Solid Films 517, 2455-2460 (2009).

5. Wang, L., Li, L. \& Sun, M. Flexible chalcogenide glass microring resonator for mid-infrared emission. In 8th International Symposium on Advanced Optical Manufacturing and Testing Technologies: Design, Manufacturing, and Testing of Micro-and Nano-Optical Devices and Systems; and Smart Structures and Materials, vol. 9685, 96850 (International Society for Optics and Photonics, 2016).

6. Li, Z. et al. Functional chalcogenide na2hgsn $2 \mathrm{se} 6$ and $\mathrm{k} 2 \mathrm{mnge} 2 \mathrm{se} 6$ exhibiting flexible chain structure and intriguing birefringence tunability. Inorg. Chem. (2020).

7. Liu, L. et al. Coherent mid-infrared supercontinuum generation in all-solid chalcogenide microstructured fibers with all-normal dispersion. Opt. Lett. 41, 392-395 (2016).

8. Zhang, B. et al. Low loss, high na chalcogenide glass fibers for broadband mid-infrared supercontinuum generation. J. Am. Ceram. Soc. 98, 1389-1392 (2015).

9. Dai, X., Liu, X., Liu, L., Zhu, B. \& Fang, Z. A novel image-guided ft-ir sensor using chalcogenide glass optical fibers for the detection of combustion gases. Sens. Act. B: Chem. 220, 414-419 (2015).

10. Mirov, S. B. et al. Progress in mid-ir lasers based on cr and fe-doped ii-vi chalcogenides. IEEE J. Sel. Top. Quantum Electron. 21, 292-310 (2014).

11. Yin, W., Feng, K., Hao, W., Yao, J. \& Wu, Y. Synthesis, structure, and properties of li2in2mq6 ( $m=s i$, ge; $q=s$, se): a new series of ir nonlinear optical materials. Inorg. Chem. 51, 5839-5843 (2012).

12. Yin, W., Zhou, M., Iyer, A. K., Yao, J. \& Mar, A. Noncentrosymmetric quaternary selenide ba23ga8sb2se38: Synthesis, structure, and optical properties. J. Alloy. Compd. 729, 150-155 (2017).

13. Zheng, X. et al. Bandgap engineering of cu2sn (s, se) 3 semiconductor nanocrystals and their applications in thin film solar cells. J. Alloy. Compd. 728, 322-327 (2017).

14. Sales, B., Mandrus, D. \& Williams, R. K. Filled skutterudite antimonides: a new class of thermoelectric materials. Science 272, 1325-1328 (1996).

15. Chung, D.-Y. et al. Csbi4te6: A high-performance thermoelectric material for low-temperature applications. Science 287, 1024-1027 (2000).

16. Venkatasubramanian, R., Siivola, E., Colpitts, T. \& O’quinn, B. Thin-film thermoelectric devices with high room-temperature figures of merit. Nature 413, 597-602 (2001).

17. Woods-Robinson, R. et al. Wide band gap chalcogenide semiconductors. Chem. Rev. 120, 4007-4055 (2020).

18. Liu, M.-L., Chen, I.-W., Huang, F.-Q. \& Chen, L.-D. Improved thermoelectric properties of cu-doped quaternary chalcogenides of cu2cdsnse4. Adv. Mater. 21, 3808-3812 (2009).

19. Sevik, C. \& Çağın, T. Ab initio study of thermoelectric transport properties of pure and doped quaternary compounds. Physical Review B 82, 045202 (2010).

20. Ibáñez, M. et al. Cu2zngese4 nanocrystals: synthesis and thermoelectric properties. J. Am. Chem. Soc. 134, 4060-4063 (2012).

21. Zeier, W. G. et al. Bond strength dependent superionic phase transformation in the solid solution series cu 2 zngese $4-\mathrm{x} \mathrm{s}$ x. J. Mater. Chem. A 2, 1790-1794 (2014).

22. Navrátil, J. et al. Thermoelectric properties of cu 2 hgsnse 4-cu 2 hgsnte 4 solid solution. J. Electron. Mater. 43, 3719-3725 (2014).

23. Bekki, B. et al. Theoretical study of structural, elastic and thermodynamic properties of cu2mgsnx4 ( $\mathrm{x}=\mathrm{s}$, se and te) quaternary compounds. Comput. Condens. Matter 18, e00339 (2019).

24. Altosaar, M. et al. Cu2zn1-x cdx sn (se1-y sy) 4 solid solutions as absorber materials for solar cells. Phys. Status Solidi (a) 205, $167-170$ (2008).

25. Altosaar, M. et al. applications and materials science. Phys. Stat. Sol. (a) 205, 167-170 (2008)

26. Khyzhun, O., Bekenev, V., Ocheretova, V., Fedorchuk, A. \& Parasyuk, O. Electronic structure of cu2zngese4 single crystal: Ab initio fp-lapw calculations and x-ray spectroscopy measurements. Phys. B 461, 75-84 (2015).

27. Jiang, H., Dai, P., Feng, Z., Fan, W. \& Zhan, J. Phase selective synthesis of metastable orthorhombic cu 2 znsns 4. J. Mater. Chem. 22, 7502-7506 (2012).

28. Levcenco, S. et al. Polarization-dependent electrolyte electroreflectance study of cu2znsis4 and cu2znsise4 single crystals. J. Alloy. Compd. 509, 7105-7108 (2011).

29. Li, Y. et al. Electronic, optical and lattice dynamic properties of the novel diamond-like semiconductors li2cdges 4 and li2cdsns4. J. Phys.: Condens. Matter 23, 225401 (2011).

30. Steinhagen, C. et al. Synthesis of cu2znsns4 nanocrystals for use in low-cost photovoltaics. J. Am. Chem. Soc. 131, 12554-12555 (2009). 
31. Chen, S., Gong, X., Walsh, A. \& Wei, S.-H. Electronic structure and stability of quaternary chalcogenide semiconductors derived from cation cross-substitution of ii-vi and i-iii-vi 2 compounds. Phys. Rev. B 79, 165211 (2009).

32. Schnabel, T., Löw, M. \& Ahlswede, E. Vacuum-free preparation of 7.5 efficient cu2znsn (s, se) 4 solar cells based on metal salt precursors. Sol. Energy Mater. Sol. Cells 117, 324-328 (2013).

33. Fella, C. M., Romanyuk, Y. E. \& Tiwari, A. N. Technological status of cu2znsn (s, se) 4 thin film solar cells. Sol. Energy Mater. Sol. Cells 119, 276-277 (2013).

34. Vu, T. V. et al. Electronic structure and optical properties of ag2hgsnse4: First-principles dft calculations and $\mathrm{x}$-ray spectroscopy studies. J. Alloy. Compd. 732, 372-384 (2018).

35. Liu, B.-W. et al. Synthesis, structure, and optical properties of the quaternary diamond-like compounds $\mathrm{i} 2$-ii-iv-vi4 (i=cu; $\mathrm{ii}=\mathrm{mg}$; iv= si, ge; vi= s, se). J. Solid State Chem. 204, 251-256 (2013).

36. Hong, A., Yuan, C. \& Liu, J. Quaternary compounds ag2xyse4 ( $\mathrm{x}=\mathrm{ba}, \mathrm{sr} ; \mathrm{y}=\mathrm{sn}$, ge) as novel potential thermoelectric materials. J. Phys. D Appl. Phys. 53, 115302 (2020).

37. Yin, W., Iyer, A. K., Li, C., Yao, J. \& Mar, A. Noncentrosymmetric chalcogenides baznsise4 and bazngese4 featuring one-dimensional structures. J. Alloy. Compd. 708, 414-421 (2017).

38. Dou, Y. et al. Srcdges4 and srcdgese4: promising infrared nonlinear optical materials with congruent-melting behavior. Crystal Growth Des. 19, 1206-1214 (2019).

39. Li, C., Li, X., Huang, H., Yao, J. \& Wu, Y. Ba2asgase5: A new quaternary selenide with the novel [asgase5] 4-cluster and interesting photocatalytic properties. Inorg. Chem. 54, 9785-9789 (2015).

40. Liang, F., Kang, L., Lin, Z. \& Wu, Y. Mid-infrared nonlinear optical materials based on metal chalcogenides: Structure-property relationship. Crystal Growth Des. 17, 2254-2289 (2017).

41. Yang, Y., Wu, K., Zhang, B., Wu, X. \& Lee, M.-H. Infrared nonlinear optical polymorphs $\alpha$-and $\beta$-srcu2sns4 exhibiting large second harmonic generation responses with requisite phase-matching behavior. Chem. Mater. 32, 1281-1287 (2020).

42. Yang, Y., Wu, K., Wu, X., Zhang, B. \& Gao, L. A new family of quaternary thiosilicates sra 2 sis 4 (a=li, na, cu) as promising infrared nonlinear optical crystals. J. Mater. Chem. C 8, 1762-1767 (2020).

43. Kresse, G. \& Hafner, J. Phys. Rev. B 47, 558 (1993).

44. Kresse, G. \& Furthmüller, J. Comput. Mater. Sci. 6, 15 (1996).

45. Ching, W.-Y. \& Rulis, P. Electronic structure methods for complex materials: the orthogonalized linear combination of atomic orbitals (Oxford University Press, Oxford, 2012).

46. Perdew, J. P., Burke, K. \& Ernzerhof, M. Generalized gradient approximation made simple. Phys. Rev. Lett. 77, 3865 (1996).

47. Monkhorst, H. J. \& Pack, J. D. Special points for brillouin-zone integrations. Phys. Rev. B 13, 5188 (1976).

48. Dharmawardhana, C., Bakare, M., Misra, A. \& Ching, W.-Y. Nature of interatomic bonding in controlling the mechanical properties of calcium silicate hydrates. J. Am. Ceram. Soc. 99, 2120-2130 (2016).

49. Adhikari, P., Khaoulaf, R., Ez-Zahraouy, H. \& Ching, W.-Y. Complex interplay of interatomic bonding in a multi-component pyrophosphate crystal: K2mg (h2p2o7) 2·2h2o. R. Soc. Open Sci. 4, 170982 (2017).

50. Poudel, L., Tamerler, C., Misra, A. \& Ching, W.-Y. Atomic-scale quantification of interfacial binding between peptides and inorganic crystals: The case of calcium carbonate binding peptide on aragonite. J. Phys. Chem. C 121, 28354-28363 (2017).

51. San, S., Li, N., Tao, Y., Zhang, W. \& Ching, W.-Y. Understanding the atomic and electronic origin of mechanical property in thaumasite and ettringite mineral crystals. J. Am. Ceram. Soc. 101, 5177-5187 (2018).

52. Hasan, S., Adhikari, P., Baral, K. \& Ching, W.-Y. Conspicuous interatomic bonding in chalcogenide crystals and implications on electronic, optical, and elastic properties. AIP Adv. 10, 075216 (2020).

53. Hunca, B., Dharmawardhana, C., Sakidja, R. \& Ching, W.-Y. Ab initio calculations of thermomechanical properties and electronic structure of vitreloy z r $41.2 \mathrm{t} \mathrm{i} 13.8 \mathrm{c} \mathrm{u} 12.5 \mathrm{n}$ i $10 \mathrm{~b}$ e 22.5. Phys. Rev. B 94, 144207 (2016).

54. Ching, W.-Y. et al. First-principles study in an inter-granular glassy film model of silicon nitride. J. Am. Ceram. Soc. 101, 2673-2688 (2018).

55. Poudel, L., Twarock, R., Steinmetz, N. F., Podgornik, R. \& Ching, W.-Y. Impact of hydrogen bonding in the binding site between capsid protein and ms2 bacteriophage ssrna. J. Phys. Chem. B 121, 6321-6330 (2017).

56. Adhikari, P. et al. Intra-and intermolecular atomic-scale interactions in the receptor binding domain of sars-cov-2 spike protein: implication for ace2 receptor binding. Phys. Chem. Chem. Phys. 22, 18272-18283 (2020).

57. Mulliken, R. S. Electronic population analysis on lcao-mo molecular wave functions. i. J. Chem. Phys. 23, 1833-1840 (1955).

58. Dharmawardhana, C., Misra, A. \& Ching, W.-Y. Quantum mechanical metric for internal cohesion in cement crystals. Sci. Rep. 4, 7332 (2014).

59. Rahmani, R., Amrani, B., Khodja, K.D. \& Sediki, H. Ab initio calculations of structural, mechanic, electronic and optical properties of ag 2 basn (se, s) 4 in kesterite structure. In ICREEC 2019, 349-357 (Springer, 2020).

60. Luther-Davies, B. Flexible chalcogenide photonics. Nat. Photon. 8, 591-593 (2014).

61. Li, L. et al. Integrated flexible chalcogenide glass photonic devices. Nat. Photon. 8, 643-649 (2014).

62. Deng, $H$. Theoretical prediction of the structural, electronic, mechanical and thermodynamic properties of the binary $\alpha$-as 2 te 3 and $\beta$-as2te3. J. Alloy. Compd. 656, 695-701 (2016).

63. Chiles, J. et al. Low-loss, submicron chalcogenide integrated photonics with chlorine plasma etching. Appl. Phys. Lett. 106, 111110 (2015).

64. Voigt, W. Lehrbuch der kristallphysik: (mit ausschluss der kristalloptik) Vol. 34 (BG Teubner, USA, 1910).

65. Reuß, A. Berechnung der fließgrenze von mischkristallen auf grund der plastizitätsbedingung für einkristalle. ZAMM-J. Appl. Math. Mech. 9, 49-58 (1929).

66. Hill, R. The elastic behaviour of a crystalline aggregate. Proc. Phys. Soc. Lond. Sect. A 65, 349 (1952).

67. Pugh, S. Xcii. relations between the elastic moduli and the plastic properties of polycrystalline pure metals. Lond. Edinburgh Dublin Philos. Mag. J. Sci. 45, 823-843 (1954).

68. Varshney, D., Jain, S., Shriya, S. \& Khenata, R. High-pressure and temperature-induced structural, elastic, and thermodynamical properties of strontium chalcogenides. J. Theor. Appl. Phys. 10, 163-193 (2016).

69. Ali, M. et al. First-principles study of elastic, electronic, optical and thermoelectric properties of newly synthesized k2cu2ges4 chalcogenide. J. Alloy. Compd. 781, 37-46 (2019).

70. Benkabou, A. et al. Structural, elastic, electronic and thermodynamic investigations of neptunium chalcogenides: First-principles calculations. Chin. J. Phys. 54, 33-41 (2016).

71. Heciri, D. et al. Insight into the structural, elastic and electronic properties of tetragonal inter-alkali metal chalcogenides csnax $(\mathrm{x}=\mathrm{s}$, se, and te) from first-principles calculations. Mater. Chem. Phys. 221, 125-137 (2019).

\section{Acknowledgements}

This research used the resources of the National Energy Research Scientific Computing Center supported by DOE under Contract No. DE-AC03-76SF00098 and the Research Computing Support Services (RCSS) of the University of Missouri System. N. Li thanks financially supported by the Fok Ying-Tong Education Foundation for Young Teachers in the Higher Education Institutions of China (No. 161008), the Overseas Expertise 
Introduction Project (111 project) for Discipline Innovation of China (B18038), the Key R \& D Program of Hubei province (No. 2020CFA087), the Basic Research Program of Shenzhen (JCYJ20190809120015163), the research board of the State Key Laboratory of Silicate Materials for Architectures.

\section{Author contributions}

W.C. conceived and directed the project. S.H. and K.B. performed the calculations, S.H. made all figures, S.H., W.C. and N.L. drafted the paper. All authors participated in the discussion and interpretation of the results. All authors edited and proofread the final manuscript.

\section{Competing interests}

The authors declare no competing interests.

\section{Additional information}

Supplementary Information The online version contains supplementary material available at https://doi.org/ 10.1038/s41598-021-89281-6.

Correspondence and requests for materials should be addressed to N.L. or W.-Y.C.

Reprints and permissions information is available at www.nature.com/reprints.

Publisher's note Springer Nature remains neutral with regard to jurisdictional claims in published maps and institutional affiliations.

(c) (i) Open Access This article is licensed under a Creative Commons Attribution 4.0 International License, which permits use, sharing, adaptation, distribution and reproduction in any medium or format, as long as you give appropriate credit to the original author(s) and the source, provide a link to the Creative Commons licence, and indicate if changes were made. The images or other third party material in this article are included in the article's Creative Commons licence, unless indicated otherwise in a credit line to the material. If material is not included in the article's Creative Commons licence and your intended use is not permitted by statutory regulation or exceeds the permitted use, you will need to obtain permission directly from the copyright holder. To view a copy of this licence, visit http://creativecommons.org/licenses/by/4.0/.

(C) The Author(s) 2021 